\title{
Societal implications of Sustainable Energy Action Plans: from energy modelling to stakeholder learning
}

\author{
Giovanni Bernardo ${ }^{1}$ \\ Simone D'Alessandro²
}

\begin{abstract}
This article investigates the potential impact of Sustainable Energy Action Plans (SEAPs) on local development through a two-step methodology involving participatory planning and quantitative analysis. The first phase relies on a participatory system mapping approach and generates a causal structure at the basis of the urban model. In the second phase, we transform the qualitative map into a system dynamic model which evaluates the effect of the SEAP on social, economic and environmental indicators. This methodology was applied to the case of Cascina Municipality (Italy). Through scenario analysis, we show that some indirect feedback can harm the achievement of the $20 \%$ emission reduction target. This process allows the local authority and stakeholders to evaluate the impact of emission-reduction policies on $\mathrm{CO}_{2}$ emissions and local development, thereby generating collective learning on the systemic implications of the plan. We show that this method can enhance the ambition of emission mitigation efforts by small towns.
\end{abstract}

JEL classification: Q51, Q56, R11, R41.

Keywords: sustainable energy plan, collective learning, local development, system dynamics.

${ }^{1}$ Department of Law, University of Palermo, Piazza Bologni 8, 90134 Palermo, Italy. Tel.: +39 091 23892620, email: giovanni.bernardo@unipa.it.

2 Dipartimento di Scienze Economiche, Università degli Studi di Pisa, Via Cosimo Ridolfi 10, 56124 Pisa, Italy. Tel.: +39 050221 6333, fax: +39 0502216384 , email: simone.dalessandro@unipi.it. 


\section{Introduction}

In recent years, the European Union has increasingly recognised the leading role of cities, towns and other urban areas in mitigation and adaptation strategies to deal with climate change (Dent et al., 2016, McPhearson et al., 2016). On the one hand, they consume from $60 \%$ to $80 \%$ of the energy produced in the European Union and generate around the same share of $\mathrm{CO}_{2}$ emissions (Gils et al., 2017). On the other, a broader stream of research identifies cities as severely vulnerable to climate change, raising complex challenges for future prosperity in urban areas (Hunt and Watkiss, 2011; While and Whitehead, 2013).

European Union climate change policy has rapidly moved to tackle this issue by creating a multi-level system of climate governance where local authorities should implement EU legislation (Cucchiella et al., 2017). At the same time, they should be the designers of new strategies for sustainability and the main facilitators of learning dissemination from experience and best practices (Kern, 2014). The spread of different kinds of voluntary environmental agreements is likely to incentivise urban climate governance innovations but, at the same time, makes the assessment of their success and effectiveness very arduous (van der Heijden, 2012). This calls for a critical consideration of the role of cities in climate governance, as pointed out in the Editorial (van der Heijden, Patterson, Juhola \& Wolfram, this issue).

Urban size is widely recognised as an important factor of successful governance innovations for sustainability. Innovation activities and the knowledge-based economy are more likely to flourish in cities (Homsy and Warner, 2015; Carter et al., 2015) while towns often lack organization and leadership capacities to support innovations and sustainability strategies (Wilson, 2006; Miller et al., 2009). Furthermore, most of the studies on small and medium-size towns show that, in the evaluation of energy planning, the same criteria are applied as in larger urban areas (Levesque et al., 2016; Lubell and Handy, 2009). Another important limitation is that local authorities face political and economic hurdles in managing strategies for sustainability. Indeed, there is widespread concern that any investment in energy and mitigation policies is costly and might compromise improvements in residents' wellbeing and local economic development. This argument is strengthened by the long-term effects of the economic crisis, which has reduced budget availability and the range of policy instruments through the introduction of new legislative budget constraints, e.g., the internal stability agreement (Knox and Mayer, 2012; Medda et al., 2015). Moreover, the success of sustainable planning is partly uncertain since it crucially depends on the capacity to affect citizens' behaviour (Salvia et al., 2015).

On the other hand, small municipalities are favoured by the fact that citizens and stakeholders can be easily engaged in innovative and alternative practices (Knox and 
Mayer, 2013; Levesque et al., 2016). More specifically, such an advantage can be used to experiment with new forms of governance which can be very effective in implementing mitigation and adaptation strategies. Furthermore, urbanisation problems occur less frequently in small and medium-size towns which normally have low population density, low crime rates, low air pollution and little traffic congestion (Hoppe et al., 2016). This can offer comparative advantages and allow towns to focus on fewer, effective sustainability policies that meet their scale and their specific needs (Edwards and Haines, 2007).

Starting from these considerations and given that more than $20 \%$ of the EU population lives in urban areas, there is the need to develop methods able to stimulate governance innovations for sustainability in small municipalities. To this aim, we apply a two-stage methodology to develop a tailored model in system dynamics for the Municipality of Cascina (Italy). In the first stage, we develop qualitative participatory systems mapping (PSM) to grasp the main critical causal relationships and feedback processes among a specific set of variables and indicators, starting from a simple question: how can SEAPs influence the quality of life in the area while achieving the $\mathrm{CO}_{2}$ emissions reduction target? The aim of this step is to help local politicians and administrators to select the most effective measures and to generate a collective learning process on the systemic implications of the plan. This exercise makes decision makers more confident and clearer when presenting and explaining the potential results of selected actions, enhancing the capacity of the plan to affect public environmental awareness.

In the second stage, we apply a system dynamic micro-macro model (SD3M) to assess the impact of policies and initiatives in the social, economic and environmental spheres by processing data gathered from a wide range of sources. In particular, we design an urban dynamic model able to analyse the societal implications of SEAPs at the local community level. Through extrapolations, SD3M offers the possibility to make projections and evaluate alternative short- and medium-term scenarios, based on the impact of the transformative activities set up in the selected location. The SD3M also aims to support the decision-making process of public administrators. Even though the resulting model is inherently case-dependent, the methodology can be easily replicated and standardised. The participatory phase fostered an endogenous collective learning process that in turn strengthened policy makers in implementing the energy plan. The outcome should be able to (i) assess the effects of environmental and energy policies on the socio-economic system by identifying a set of indicators; (ii) detect the set of policies that maximise the effects both in environmental and socio-economic terms; (iii) monitor the effects of policies over time and identify inefficiencies and weaknesses.

The rest of the paper is organised as follows. Section 2 gives an overview of methods and tools that can be applied in the energy planning activity and describes our conceptual 
framework. Section 3 briefly discusses the features of our case study. Section 4 presents the structure of the model and feedback between social and environmental variables. Section 5 discusses projections and alternative scenarios resulting from the SD3M simulations and Section 6 concludes the paper.

\section{Integrated energy planning: an overview of methods and tools}

The popularity of the Covenant of Mayors initiative has led scholars and private companies to develop an increasing number of procedures and analytical tools able to design and implement an SEAP. In a report for the Joint Research Centre, Cayuela et al. (2009) provide a review of tools used by municipalities to set up the SEAP and extensive technical advice to improve the design of the plan itself. These guidelines, however, fail to clarify how a shared view of the set of actions can emerge among policy makers and stakeholders.

Mirakyan and Guio (2013) provide a comprehensive review of methods and modelling approaches used for environmental and energy planning in cities and regions that cover different implementation phases, from the preparation and orientation phase to results monitoring. As they clarify, a single method or tool cannot be used in all the phases of integrated energy planning. There are several studies that seek to overcome this shortcoming by proposing tools that are able to perform more than one phase of plan implementation. Along these lines, Mirakyan et al. (2009) proposed a combined methodology that uses OTSM-TRIZ, an energy system modelling tool, and MCDA to assist the planning process and potential outcomes in the case of the French PACA region (Provence - Alpes - Côte d'Azur). Other studies merge integrated energy models with other methodologies such as GIS (Strachan et al., 2009; De Miglio et al., 2006), MCDA (Parkinson et al., 2018 ; Khan et al. 2018) or life-cycle modelling (MartínGamboa et al., 2017). Recently, Marinakis et al. (2017) presented a participatory supportive framework for the implementation of local energy planning combining a participatory approach, scenario analysis and MCDA. Furthermore, Cipriano et al. (2017) apply the Multi-Scale Integrated Analysis of Societal and Ecosystem Metabolism (MUSIASEM) to derive a set of indicators at the city level that can support decisionmaking processes.

Following this perspective, we design a two-stage methodology tailored for an Italian town which leads local actors to tackle the energy planning process. Moreover, we add to this recent stream of literature a systemic view where social, economic and environmental indicators are integrated in a holistic framework. 


\subsection{Conceptual framework}

We present an inductive approach to modelling based on PSM since there is a widespread belief that the involvement of stakeholders and policy makers at the beginning of the planning phase is acknowledged as a crucial factor to increase the credibility and impact of the analytical tools and their insights (Jakeman et al., 2006; Videira et al., 2010; Voinov et al., 2016). In this perspective, we apply a causal mapping approach that fosters the emergence of a shared view of the problems and the identification of the set of effective actions (Videira et al., 2009). This PSM approach can be defined as a methodology able to identify the main components and causal relations among the variables of a complex system in a structured way. Participatory system mapping combines the benefits of bottom-up methodology with the principles of system dynamics. To the best of our knowledge this contribution is the first application of PSM to SEAPs even if it has been applied in many similar contexts (Aikenhead et al., 2015; Inam et al., 2015; Sarriot et al., 2015). ${ }^{3}$

The objective of this approach is to identify the interactions among variables and the structure of feedback loops, detecting the direction of changes within the system. Consequently, this process could provide a better understanding of causal relations both for policy makers, stakeholders and researchers. There is double-loop learning among the actors involved in this process. The modellers would increase their knowledge on local characteristics through collection and comparison of relevant information held by different groups of players operating within the local socio-economic system. At the same time, participation would help policy makers to capture and elucidate relations among policies and sectors, proving hypotheses about the causes and effects that govern the system under consideration. The result of this participatory phase represents the structure of the quantitative model.

To transform the qualitative map into an analytical model, we use system dynamics, an approach widely used in public management and urban planning applications that permits a complex social or behavioural system to be broken down into its constituent components and then have them integrated within a holistic model. In this field, there are two types of perspective, one of which tends to analyse the impacts of specific policies in a single sector ${ }^{4}$. The second, closely related to so-called urban dynamic management, applies a simulation model describing the major internal forces controlling

\footnotetext{
${ }^{3}$ See for instance Responder projects, which aim to promote sustainable consumption by assessing potential contradictions with economic growth - taking into account aspects of green growth, non-growth and de-growth. For further information, refer to http: / / www. scp-responder.eu/.

${ }^{4}$ See for instance Shepherd (2014) on transport systems, Brailsford et al. (2004) and Viana et al. (2014) on health care, Feng et al. (2013) and Bianchi and Tomaselli (2015) on energy and environment and local strategic management.
} 
the balance of population, housing, transport and economic activities with the aim of assessing the impact of energy policies as a whole. In this field, the first model that deserves mention is Urban Dynamics, a model developed by Forrester (1969) in which the author proposed a tool able to analyse the dynamics of population, housing and industry within an urban area by considering a variety of possible strategies for public policy. ${ }^{5}$ Recently, Liu et al. (2016), Fong et al. (2009) and Feng et al. (2013) applied SD modelling to the urban energy planning process, underlining the importance of this tool in the decision making process. Caponio et al. (2015) provided a simulation model based on system dynamics applied to a medium-size Italian town which considers social and economic impacts of the policies adopted, focusing on a specific sector, residential buildings.

In line with the second approach, we consider the sectors of the city that are influenced by the SEAP, which covers different sectors such as transport, public buildings and housing, industry and households. The modules are designed so that they can be easily modified and applied in a wide range of cases and scaled up. Through the construction of different indicators and scenario analysis, our aim is to investigate the impacts of the energy plan in terms of economic wellbeing - with a specific focus on green economic growth and job creation - as well as human wellbeing, and ultimately support the decision-making process of public administrators during implementation of the programme. Moreover, after proper calibration and continuous updating of data, the model allows local authorities to monitor the effects of policies over time by identifying inefficiencies and weaknesses both in the environmental and economic domains. For this reason, the same tool can be employed during the monitoring phase of SEAP implementation. ${ }^{6}$ In this perspective, we propose circular feedback between projections and monitoring activities which strengthens the effectiveness of the plan.

As pointed out above, the system mapping approach generates collective learning through the use of system thinking and participatory planning. The analytical model can also help this process by contributing to the effectiveness of energy plans with the identification of the strengths and weaknesses of the selected policies. Moreover, scenario analysis allows uncertainty to be dealt with, showing possible paths on emissions abatement and other policy implications. In this respect, the modelling

\footnotetext{
5 After this seminal work, several models and applications were developed, the most relevant being Sanders and Sanders (2004), Swanson (2003), DuranEncalada and Paucar-Caceres (2008) and Hennessy et al. (2011).

${ }^{6}$ Delponte et al. (2017) present a detailed SD model for supporting the monitoring and evaluation phases of the SEAP in the city of Genoa (Italy). While this contribution considers several sectors, it focuses on the impact of the plan on its specific targets, i.e. energy savings and $\mathrm{CO}_{2}$ emissions reductions.
} 
activity itself has a proper learning role that might help local administrators to select environmental initiatives, increasing the resilience of the urban system.

\section{The case study}

\subsection{The Municipality of Cascina}

Cascina is an Italian municipality in the province of Pisa with a area of $79 \mathrm{~km}^{2}$. The population of the urban area (about 45,000) has almost doubled since the 1970s, and has grown at an average of $1.2 \%$ per annum since 2002 . The reason for such growth is due to an active migration of households from urban areas nearby ${ }^{7}$, which are attracted by various factors, such as the low house prices, the improvement in public services and the establishment of commercial and productive activities. Cascina is a fairly representative Italian town. The average income in Cascina is very similar to the national average (in $2015, € 14,248$ and $€ 13,713$ respectively); the same holds for the average age of the population (44.6 and 44.9). Moreover, more than a quarter of Italian residents live in towns with a population size between 20,000 and 80,000 . The average surface area of this group of municipalities is $85.88 \mathrm{~km}^{2}$, with an average of about 35,500 residents. Thus, if small and medium-size towns are acknowledged to be a crucial actor in the EU's Climate Action strategy, Cascina is an illustrative example to analyse the strengths and weaknesses of energy planning implementation in such towns. Furthermore, the municipality of Cascina joined the Covenant of Mayors in 2013. ${ }^{8}$ Hence the research group from the University of Pisa started monitoring the process from the beginning, and was able to implement participatory activity before the presentation of the SEAP.

According to the baseline emissions inventory (BEI), almost 470,000 MWh of energy was consumed by the municipality of Cascina in the reference year, i.e. 2008, generating 175,000 tons of $\mathrm{CO}_{2}$. Per capita emissions were around $4.05 \mathrm{tCO}_{2}$, below the national Italian average of almost $7.5 \mathrm{tCO}_{2}$ in $2008 .{ }^{9}$ This difference is due to two main factors. First of all, the BEI does not include some sources of emission such as those from organic decomposition of soil and the agricultural sector, waste treatment plants and public transport. Secondly, the proxy for transport emissions is given by the amount of fuel sold locally in the reference year. Given the high share of commuters (about one

${ }^{7}$ Especially from Empoli, Pisa and Pontedera

${ }^{8}$ Given the size of the town and the consequent limits of the administrative structure, local administrators were not prepared to draw up such a specific energy plan. For this reason, they decided to entrust the development of the Baseline Emissions Inventory (BEI) and SEAP to external auditors - namely, GreenGea. For further details see http://www.greengeasnc.it/

${ }^{9}$ For more information see http://edgar.jrc.ec.europa.eu/overview.php?v=\$CO_2\$ts1990-2014. 
third of the population), this value seems to be underestimated. Nevertheless, transport has the greatest impact on $\mathrm{CO}_{2}$ emissions, followed by the housing sector and businesses. Table 1 shows the aggregate emissions and energy use per sector and their share.

\subsection{Participatory System Mapping}

Following the methodology discussed in section 2.1, we organised two meetings with local administrators and officials in order to create the causal loop diagram which represents the basis of the quantitative model. The workshop was attended by the Mayor of Cascina, all the members of the local governing council ${ }^{10}$ and external energy planning consultants ${ }^{11}$.

The discussion at the first meeting focused on the impact of direct and indirect actions on the attractiveness and quality of life in the surrounding area. The discussion was initiated by explaining the meaning of system thinking and the main elements and symbolisms of system mapping. The participants developed a causal map by answering the following question: "How can SEAPs influence the quality of life in the area while achieving the $\mathrm{CO}_{2}$ emissions reduction target?" After defining macro-sectors and the main variables, different policies were considered with a view to clarifying the emerging feedback loops within the socio-economic system. Figure 1 shows the causal system obtained through meeting discussions. Three main building blocks can be identified: the first draws up public policies that are chosen by policy makers and are influenced by local stakeholders as well as budget constraints and resource availability. Planned energy policies might affect the socio-economic system through the industrial and commercial sectors, the municipal budget, social services and the environment. During the discussion, we also highlighted the potential impact on the transport system and the green economy. Finally, the potential change in the local system could modify the

${ }^{10}$ In particular, we emphasise the presence of the Councillor for Urban Planning and Transport (representing some publicly owned corporations - namely the school transport provider, Amico Bus, and the transport company of northern Tuscany, CTT); the Councillor for Agriculture and Environmental Policies (representing some publicly owned corporations - namely Toscana Energia SPA and AEP, energy agencies respectively at regional and provincial level, the waste management companies RETIAMBIENTE SPA and GEOFOR PATRIMONIO SRL, the Cascina aqueduct and sewer authority, CERBAIE S.P.A); the Councillor for Finance; the Councillor for Trade and Local Development (representing some publicly owned corporations - namely ECOFOR SERVICE SPA, the agency for planning, monitoring and control of industrial plants) and Polo Tecnologico SPA).

${ }^{11}$ GreenGea. For further details see

http://www.greengeasnc.it/GreenGea/Home.html 
attractiveness of the area that may affect both the dynamics of the population and private investments.

Starting from the general model, the purpose of the second meeting was to unbundle the macro-structure identifying the main variables of the system. The goal was to detect positive and negative feedbacks that occur between the system's components and to analyse possible effects resulting from the implementation of energy policies. The resulting causal map (fig A.1) was then processed, generating three qualitative submodels: the energy sector (fig. A.2), the transport system (fig.A.3) and the economy module (fig. A.4). The most evident contribution of PMS was to clarify the impacts of the energy plan on the socio-economic system, analysing the strengths and weaknesses of the actions. In particular, local administrators felt the need to use a simulation model to monitor the effectiveness of policies during the implementation of SEAP. This statement is corroborated by the fact that this project was included as one of the SEAP's activities adopted by the Municipality of Cascina (see fig. A.5).

\subsection{Cascina's SEAP}

Cascina's SEAP consists of 32 direct and indirect actions that aim to lower $\mathrm{CO}_{2}$ emissions levels and the use of fossil fuels. For the sake of argument, we aggregate the actions into three macro-categories: (i) direct actions on public emissions - 1-9 and 31, (ii) direct actions on private emissions - 18-20 and 22-30, (iii) indirect actions for households and firms - 12-15, 17, 21 and $32 .{ }^{12}$

The actions of the first group aim to: a) improve energy efficiency of public buildings and street lighting; b) build renewable energy power plants; c) replace the municipal fleet with greener vehicles. Overall emissions reduction represents just a small fraction of city emissions, yet it halves municipal direct emissions. Such an outcome, direct actions involving public buildings and installations, could also lead to an increase in citizen awareness, fostering in turn green household investments.

The second group of interventions concerns policies aiming to enhance the quality of the transport system and increase renewable energy production. With respect to the first sub-group of initiatives, the idea is to create a social transport scheme that improves urban mobility, by strengthening transport services and providing a series of other services, including car-sharing, bike-sharing and walking bus. The second sub-group of policies aims to provide clean energy for Cascina's business district through direct investment in renewable energy facilities.

12 Tables 2-4 describe each action and its expected contribution in $\mathrm{CO}_{2}$ emissions reduction. Outside these three groups, there is action 10 -i.e. the development of the model discussed in this paper, action 11 - a specific survey, and action 16 - a change in regulation governing land use. 
The third group of actions concerns indirect policies to stimulate green investments and promote good practices among households and firms. The main action is to establish an energy desk where citizens and local entrepreneurs can obtain a wide range of information regarding low carbon vehicles, small renewable power plants and the rational use of energy sources. In addition, the aim is to keep stakeholders informed of the latest tax and economic incentives for energy efficiency interventions and renewable energy promoted both at regional, national and European level. The effectiveness of the energy desk would be enhanced through a series of specific campaigns seeking to sensitise the public about the use of public transport and green investment opportunities. Finally, two specific actions introduce a local revolving loan scheme, with low or zero interest rates, for multiple small investments in energy saving.

The final report estimates that the energy plan should bring about an emissions reduction of $37,000 \mathrm{tCO}_{2}$, which corresponds to an abatement of $21.3 \%$ with respect to the baseline year, once it becomes fully operational. Per capita emissions are estimated to decrease from 4.05 in 2008 to $3.19 \mathrm{tCO}_{2}$ in 2020 . Graph 2 shows the dynamics of carbon emissions according to the implementations of the energy action plan.

\section{Quantitative Analysis}

\subsection{Model Overview}

Starting from the causal loop diagram, we transformed it into a quantitative model based on system dynamics. The structure of the final model is complex because it consists of 28 modules that interact with one other through a series of connections. ${ }^{13}$ Three subsystems can be highlighted: the transport module, the building module and the economy module. energy

The interaction between SEAP policies and the transport system is shown in figure 3. The main objective of this module is to determine the modal split, defined as the percentage of commuters using a specific transport mode. Assuming that population growth increases the demand for public transport and the stock of private vehicles, this module is divided into two main blocks: the first defines demand for transport as the number of public transport users and hence determines the share of people choosing public services; the second block analyses the use of private transport, estimating the average number of kilometres, fossil energy use and $\mathrm{CO}_{2}$ emissions for each type of vehicle.

The energy module comprises three blocks that establish the level of energy consumption for households and the public administration, the renewable energy

${ }^{13}$ For a detailed description of the model, see Bernardo (2016). 
capacity and building efficiency capacity. Figure 4 captures the relationship between population dynamics, housing and energy consumption of buildings. An increase in population stimulates housing construction and the occupation of uninhabited dwellings. The second block focuses on the buildings and services connected with the local municipality. We simply assume that energy demand is constant over time and it decreases with energy policies. The third block considers investments in energy efficiency which improve the energy performance index of dwellings, and investments in renewable energy which instead reduce energy expenditure.

While the effect of direct policies on green investments is understandable and the relationships among system components are easily modelled, indirect policies deserve to be explored in depth as their effectiveness on the environmental awareness of citizens might be uncertain. In this regard, the United Nations Economic Commission for Europe (Sivaev et al., 2013) has already pointed out that household consumption can be modified through public policies such as specific campaigns on energy saving ${ }^{14}$. Indeed, there is a growing body of academic literature which focuses on consumer behaviour and provides evidence for the wasting of energy at home, especially during unoccupied hours (Barbu et al., 2013; Masoso and Grobler, 2010). In this study, we are not interested in discussing specific policies to discourage such adverse behaviour and to improve public awareness of sustainable energy use. In line with the existing literature on system dynamics modelling (Oosthuizen and Pretorius, 2015; Sveiby et al., 2002), awareness accumulation increases proportionally to the intensity of the SEAP measured by total investment in energy policies. The awareness measure is likely to affect the average consumption of methane and electricity for buildings and reduce the average annual distance travelled using vehicles. Moreover, we extend the impact of the awareness measure on investments in solar panels and in promoting energy efficiency.

Figure 5 describes the economy module by focusing on the relation between income, value added of firms and employment. In order to take into account the effects of policies at the economic level, we define net income as disposable income plus national incentives for green investment, less energy expenditures, debt repayment and SEAP costs directly financed by the municipality. ${ }^{15}$. Net income is a crucial variable of the model for two main reasons: first, it affects the revenues of firms and employment; secondly it increases the attractiveness of the area, thereby incentivising immigration.

Expenditure on efficiency, renewable energy and new cars raises the indebtedness of households and firms at least in the short-medium term, leading to a reduction of

${ }^{14}$ For a discussion of this topic, see for instance Hong et al. (2016), Team (2011), Barbu et al. (2013).

15 Note that a significant share of total SEAP funding comes from Regional, National or European authorities 
disposable income. On the other hand, population growth increases the level of aggregate disposable income that encourage business investment and local consumer spending. Accordingly, this mechanism will generate a virtuous circle with positive effects on the local economy. This process generates two different consequences, namely an improvement in the internal level of employment and an increase in the demand for energy and in $\mathrm{CO}_{2}$ emissions. These trade-offs will be explored using scenario analysis.

\subsection{Data sources and Calibration}

The main source of data used to calibrate and simulate the model was that collected by the Municipality of Cascina for the implementation of the baseline emission inventory. However, the information received from this data source was not sufficient to extend the model and to produce the desired simulated results. In order to fill this gap, we rely on other sources of data which will be discussed in this subsection.

The first sector of our analysis is households and housing. We use the demographic data from ISTAT ${ }^{16}$, which provides information from the ten-yearly census combined with various other sources collected by the local registry office. We then divide inhabitants into four cohorts groups based on age. Data on the total housing stock from 2008-2014 are obtained from ISTAT. In addition, we obtain the number of apartments where energy utilities were activated in 2008 and the annual average consumption of energy by source (electricity and methane) from the BEI dataset. We assume that housing built after 2006 has a differentiated efficiency rate compared with those previously made with a lower average energy consumption.

Data requirements for the transport sector are mainly obtained from the BEI dataset with minor additions from other sources. The number of cars and motorbikes per household is obtained from $\mathrm{ACI}^{17}$ and from a collection of reports provided by the Province of Pisa called "Noi Pisa ${ }^{18 "}$. The stock of private vehicles are then classified into primary and secondary, where the former refers to the main household vehicle while the latter represents the vehicle least used. Moreover, we differentiate cars by type of fuel and emission standard (from Euro 1 to Euro 6). Information about the average distance travelled by car per year is processed using the ACI dataset. The same data source was used to estimate the ratio of kilometres travelled per unit of fuel, differentiating by type of emission standards. To assess the dynamics of the modal transport share in the municipality of Cascina, we take into account local microdata provided by ISTAT relative to the ten-yearly census in 1991, 2001 and 2011.

\footnotetext{
${ }^{16}$ Italian National Institute of Statistics: http://demo.istat.it/archive.html

17 The Italian Automobile Club http://www.aci.it/laci/studi-e-ricerche/dati-estatistiche/open-data.html

${ }^{18} \mathrm{http}: / / \mathrm{www}$. provincia.pisa.it/uploads/Noi\%20Pisa\%20Completo.pdf
} 
Data concerning the economic sector were collected using different sources. In particular, the value added of the traditional economic sector was extracted from IRPET $^{19}$ while the average income of workers and pensioners was retrieved from the annual self declaration of individual income provided by $\mathrm{MEF}^{20}$. We collected the number of employees in the traditional sector and retirees from the ISTAT labour statistics, while to evaluate the number of green workers we relied on the national average, though we acknowledge this measure should be treated with some caution.

Data collection in the energy sector was one of the most difficult tasks of this study, since we utilised a massive combination of data sources that include different technical reports. Data relating to the number of small photovoltaic plants and the relative module capacity were obtained from the BEI while those relating to the Government incentive scheme were retrieved from reports of the Ministry of Infrastructure. The estimated average annual cost of a $1 \mathrm{kw}$ PV module as well as conversion efficiency and annual average electricity production was obtained through a combination of different technical reports provided by ENEA ${ }^{21}$ (Terzini et al., 2011), GSE ${ }^{22}$ (GSE, 2014) and Deutsche Bank (Booream-Phelps and Shah, 2015). Annual investment in energy efficiency, which includes types of plants and their relative cost and savings in terms of energy consumption and $\mathrm{CO}_{2}$, was retrieved from the annual report of energy efficiency provided by ENEA (Nocera, 2014) ${ }^{23}$. Finally, the energy price statistics relative to electricity and methane, also differentiated by household and industrial consumers, and by type of fossil fuel, were extracted from Eurostat ${ }^{24}$.

${ }^{19}$ Regional Institute for Economic Planning of Tuscany http://www.irpet.it/en/index.php

${ }^{20}$ Ministry of Economy and Finance

${ }^{21}$ Italian National Agency for New Technologies, Energy and Sustainable Economic Development

${ }^{22}$ GSE is the state-owned company which promotes and supports renewable energy sources (RES) in Italy. It fosters sustainable development by providing support for renewable electricity (RES-E) generation and by taking action to build awareness of environmentally-efficient energy uses. Moreover, it is part of the National Statistics System (SISTAN).

${ }^{23}$ For convenience, we cite the most recent version of this technical report while we also used previous versions for data collection.

${ }^{24} \mathrm{http}: / /$ ec.europa.eu/eurostat/statisticsexplained/index.php/Energy_price_statistics 
Among the various parameter calibration processes available (Oliva, 2003), we use three main approaches, namely average rate of change ${ }^{25}$, OLS regression and optimization algorithm. While the first two are very widespread in system dynamics, the third deserves a brief explanation. An optimization algorithm is employed when two conditions are fulfilled. The first condition requires that there be enough data in timeseries format for the dependent variable and the second that the change be driven by a combination of factors, at least involving two variables. For example, it is reasonable to assume that the annual change in the average kilometres travelled per car is determined by different factors such as the price of fuel, per capita income and access to public transportation. Thus, calibration using an optimization algorithm seeks to minimise the distance between the simulated and the real value of the dependent variable through an iterative process of various combinations of factors which we believe to have a fair amount of correlation. In other words, the observed time-series data of the dependent variable take the role of the constraint in the optimization process. The optimization algorithm will therefore run the model many times to find the best match for all combinations which minimises the distance between the simulated and the observed time-series. To achieve this we perform two methods. We could start by assigning random values for the combination of variables and then allow the simulation to find the optimum combination ensuring minimum distance. Alternatively, if we have some theoretical background which helps assign not random values but values in the form of a interval, the optimization process would be more efficient in nature. We used this methodology to calibrate population dynamics, demand for public transport and average distance travelled per car.

\section{Baseline scenarios}

In the first scenario, we show a replication of the results contained in the energy plan drawn up by the Municipality of Cascina. The main assumption is that, without any intervention, the level of energy consumption would be constant over time at the 2008 level. Energy policies will bring about a reduction in the amount of energy use through investments in energy efficiency and an increase in renewable energy urban production (i.e. both small- and large-scale investments in renewable power plants). In this case, we observe that the total emissions will decrease over time, thus achieving the proposed $20 \%$ reduction of $\mathrm{CO}_{2}$ in 2020 (see fig. 6) ${ }^{26}$.

Table 5 shows $\mathrm{CO}_{2}$ emissions reduction by sector, comparing the result of the Cascina SEAP versus the simulated model. Total reduction in $\mathrm{CO}_{2}$ is almost the same,

25 The average rate of change is extensively used in cases where one variable is directly connected to another such that the change in one causes a positive or negative variation to the other

${ }^{26}$ The simulation period starts in 2008 (period zero in the figures) and is run for 13 years 
while there are significant differences across sectors. Model emissions reduction projections are significantly lower in the case of households and firms with respect to the official Cascina SEAP, while in the transport and public sector, emissions savings are higher in the model. We believe that this discrepancy at the cumulative level is due to the fact that, without taking into account the economic cost of private investments in renewable energy, the municipal SEAP overestimates this effect.

An explanation for the higher savings observed in the transport sector is linked to the national data on the demand for fossil fuels, which displayed a decrease from 2008 to 2014, mainly due to the higher fuel prices. Accordingly, we embed this fact into our model and observe that the average annual distance travelled decreases when fuel prices increase. The positive disparity observed in the saving of $\mathrm{CO}_{2}$ in the public sector in our model is linked with an assumption that production efficiency of renewable energy power plants would increase over time and therefore the effect of direct investments would be higher than those estimated in the Cascina SEAP.

The hypothesis under which total energy consumption and total emission level are stable from 2008 to 2014 appears to be unrealistic since the total population has increased within the period considered. Population growth automatically leads to an increase in energy use, mainly in housing and private transport sectors, and generates other indirect effects that we consider in our model. In particular, we introduce some parameters that capture the rebound effect, according to which technological progress increases efficiency but also the use of the good. We also incorporate the price of fossil fuel and electricity with an exogenous growth rate. Based on the available data, we additionally take into account the fact that the price of solar panels has been decreasing over time and the efficiency in solar energy production has improved. We run two sets of simulations including the feedback prompted by population dynamics by comparing the business as usual (BAU) scenario - without energy policies - with two SEAP bounding scenarios where we explore the potential effects of energy policies. The bounding methodology estimates the upper and lower bounds through the use of sensitivity analysis.

\subsection{Scenario analysis: green investment}

The first scenario analyses the effect of SEAP by assuming a certain degree of uncertainty on green investments. The upper bound scenario, called SEAP, does not allow the $20 \%$ reduction target to be met since only $90 \%$ of the programme is implemented (see fig.7g). The lower bound, called SEAP 20\%, meets the target since the programme is fully implemented and the effect of indirect actions on green investment is stronger than expected. Figure 7 presents the results in terms of per capita net income, employment both in the traditional and green sectors, investment in the green sector, energy use and expenditure and the consequent carbon emissions for the three scenarios. In the graphical analysis, we consider simulation starting from period 6 to display scenario differences more clearly. 
Starting from the BAU scenario, we observe that a low level of investment in the sustainable energy sector does not produce any significant effect in terms of carbon emissions abatement (fig. $7 \mathrm{~g}$ ). This is mainly due to the fact that per capita reduction in the use of non-renewable energy is offset by the increase in energy use due to the growing population. The energy expenditure index increases over time due to the twofold effect of higher demand for a fossil energy source and the relative fuel price rise (fig.7a). ${ }^{27}$ By contrast, under the SEAP and SEAP 20\% scenarios, a high level of investment in renewable energy, efficiency and transport potentially reduce both $\mathrm{CO}_{2}$ emissions (fig.7g) and energy expenditure (fig.7a). The only negative effect in these scenarios is the increasing level of private debt (fig. 7b) which is more visible in the SEAP $20 \%$ case.

The SEAP programme brings about changes that profoundly affect the socioeconomic system. Net income first decreases below the BAU level-due to public SEAP costs and private investment. However, this initial loss in income is recovered after a few periods (fig.7c). This improvement is possible thanks to the decline in energy expenditure and to the development of local businesses in the green sector. A further explanation of this result is that green power plants and other actions planned by the local authority (e.g. public lighting, biomass and geothermal power plants or parabolic power plants) - being technologically advanced - require know-how from firms and manpower skills which are lacking in the area. Thus it is reasonable to assume that the economic benefits will not be concentrated at the local level but will flow outside the local economy, causing a small loss of income at least initially. However, such a loss of income would only be temporary. The model predicts the growth of several local firms and associated manpower with a lag due to the continuous flow of investments in solar panels and in energy efficiency. The level of employment in the green sector will grow over time, with a positive effect on the local economy and income (fig.7d). We highlight the fact that the SEAP 20\% scenario w.r.t. the SEAP scenario may be less appealing as high private debt nullifies the positive income effect in the long run (fig. $7 c$ ).

Improvements in public transport and other services based on the sharing community principles increase the percentage of commuters in the SEAP and SEAP 20\% scenarios (fig.7e), resulting in an abatement of $\mathrm{CO}_{2}$ (fig.7g). Moreover, such actions slightly decrease the stock of "second" cars (fig.7e), fostering the decline in demand for fossil fuel. The indirect effects of transport policies considered in the SEAP programme also stimulate the efficiency of private vehicles by hastening the replacement of old cars. Such initiatives could significantly reduce fossil fuel consumption. However, considering the rebound effect, we assume that people with more efficient cars tend to

27 All the indices are built taking 2008 as the base year, i.e. $x_{2008}=100$ for any variable $x$. 
increase their car use (measured in kilometres), partly offsetting $\mathrm{CO}_{2}$ emissions reductions. Figure $7 \mathrm{f}$ shows that the rebound effect increases the annual distance travelled by cars. This repercussion is higher in the SEAP 20\% scenario than in the SEAP, even if fuel consumption declines more rapidly.

\subsection{Scenario analysis: environmental awareness}

In this subsection, we compare the BAU and the upper bound (SEAP) discussed above with a new scenario, called SEAP AW, which represents the new lower bound. In this case, we assume that indirect policies, such as public campaigns and a green energy desk, are sufficiently effective to raise public awareness of energy saving and promote a more sustainable use of transport. Figure $8 \mathrm{~g}$ shows that awareness reinforces the effect of local energy policies, ensuring the achievement of $20 \%$ reduction in $\mathrm{CO}_{2}$ emissions. Table 6 shows a comparison between some crucial variables under the three scenarios. SEAP AW shows significant savings in terms of energy consumption over the BAU and SEAP scenarios. We note that with awareness, the average use of electricity and methane decreases by $20 \%$ and $5 \%$ respectively. When the average distance travelled by car is considered, a reduction of approximately $7 \%$ and $5 \%$ is achieved. Finally, SEAP AW displays a positive investment in renewable energy, registering about $35 \%$ with respect to the SEAP while investment in solar panels increases by $25 \%$.

Now, we compare the results of SEAP AW with those obtained by SEAP 20\%. The level of private debt (fig.8b) decline in the first case while it rises in the second. Moreover, the increase in awareness leads to lower consumption of energy, thus reducing energy bills (fig.8a). Consumers thus receive some benefit in terms of higher net income (fig.8c). Figures $8 \mathrm{e}$ and $8 \mathrm{f}$ show that awareness can significantly reduce the use of private vehicles, nullifying the rebound effect that was present in the SEAP 20\% scenario (cf. fig. 8e and fig.7f).

\subsection{Discussion}

Given the initial lack of data, we claim that the model's forecasts are not truly robust. To improve its predictive capacities, we need to upload the model with data from the mid-term monitoring phase. This process might ensure better calibration of parameters, more accurate projections and the identification of corrections which could increase the probability of achieving the $20 \%$ emissions target. However, since the set of possible scenarios under the two boundaries is fairly realistic, we can conclude that the SEAP implemented by the municipality of Cascina is unlikely to reach the $20 \%$ emissions target since two conditions are necessary: a) the programme must be fully implemented; b) the effect of indirect interventions must be more incisive than that expected on the SEAP. We also stress that scenario analysis remains very interesting as it gives important indications with respect to the potential socio-economic implications of different energy policies. 
At the end of 2015, the results of the quantitative model were presented during a public event organised by the University of Pisa which was attended by a delegation of the municipal administration of Cascina and by the external energy consultants. The strengths and weaknesses of the Cascina plan were discussed during the seminar, as well as possible adjustments or improvements to ensure the greenhouse gas emissions target. The critical points highlighted by our analysis were constructively accepted by local administrators, who underlined the importance of the monitoring phase not only to assess the current state of direct interventions but also to gain insights into critical issues and limitations concerning indirect interventions. Moreover, municipal administrators confirmed their availability to carry on the partnership with our research group since the potential of the tool was acknowledged. The debate was therefore followed by an informal commitment of the local trustees to produce mid-term monitoring data, planned at the end of 2016, available in order to improve the accuracy of model simulations.

In June 2016, there was a change in Cascina's local government after the local elections. The new local authority reshaped the political and administrative staff in charged of SEAP implementation. This reshuffle undermined the continuity of the plan and delayed the delivery of the monitoring reports to the point that the new administration is now planning to sign a new SEAP according to the new directives of the Covenant of Mayors. These circumstances confirm the importance of the involvement of many stakeholders in the planning phase - such as civil society, NGOs, environmental associations, etc. - which might guarantee the continuity of the implementation process even after a change in the local authority. Clearly, as pointed out by Levesque et al. (2016), the stronger the presence of these local interest groups, the more likely it is that the environmental plan is effectively implemented. Otherwise, there is the risk of involving only the ruling class and being vulnerable to policy changes which might block the learning process that had been painstakingly initiated. Moreover, limitations of voluntary agreements are highlighted (van der Heijden, 2015, 2016), especially when there is no clear scheme of penalties resulting from non-compliance with the programme. Municipality networks and multi-level governance can reduce this risk by allowing better sharing of information and promoting best practices. In this respect, Frey (2018) investigated to what extent multi-level governance can be effective at implementing policies of risk prevention and disaster mitigation.

\section{Concluding remarks}

Implementation of sustainable energy action plans is a relatively new phenomenon, projecting local policy makers as leaders of the transition to a low-carbon economy and key players in the fight against climate change. Such a bottom-up effort must be based on an accurate strategic plan, taking into consideration the peculiarities of the local economic system and identifying the most effective interventions to be made. This paper discusses a new methodology to foster governance innovations for sustainability in small and medium-size towns. In this respect, given the lack of specific skills in urban 
sustainable planning, there is the need to involve citizens and local stakeholders during the decision making process and to apply alternative governance approaches. Thanks to in-depth local knowledge, local actors can play a crucial role in identifying critical issues and their possible solutions, thus becoming principal agents of positive social changes. Furthermore, given that policy makers and stakeholders are not usually involved in policy and model design, participatory planning methodology and system thinking might be decisive factors in increasing the credibility of environmental policies by strengthening their potential impact.

We showed that system thinking provides an appropriate methodology for activating a collective learning process which supports the active engagement of local politicians and administrative staff. Through projections and alternative scenarios, the quantitative model contributes to understanding the potential effects of SEAPs in a transparent way. In particular, we find that the expected results of SEAPs in terms of $\mathrm{CO}_{2}$ emissions reductions fall short of the target when population dynamics and other endogenous feedback are taken into account. Our approach allows quantitative assessment of the contribution of cities to climate change, taking into account a systemic view of the economic and social impact of mitigation policies. This procedure offers a transparent method to evaluate the effectiveness of voluntary urban climate programmes (van der Heijden, 2018)

We explored two alternative pathways which enhance emissions reductions. The first, i.e. SEAP 20\%, strengthens the impact of SEAP indirect actions on green investments upon energy-saving technological improvement in housing and transport. This scenario allows the emissions reductions target to be achieved and stimulates the development of the green sector in the area. However, this pathway requires an increase in private investments that in turn increases the level of private debt, bringing about an intense rebound effect which tends to counterbalance the gains in efficiency. By contrast, SEAP $\mathrm{AW}$, which is based on the idea that the advancement of the plan is a clear public signal that encourages good practices inspiring both green investments and energy savings, goes beyond the target set without increasing private debt and avoids rebound.

As a general remark, the paper contributes to the scientific debate on the role of towns and cities in addressing climate change. The methodology adopted in this study shows that local climate governance can become effective when the local authority share the planning activities with local stakeholders and researchers. Such a multi-stakeholder deliberation process stimulates innovative urban climate governance which is tailored and adapted to the local area. Furthermore, the case study showed that even small towns have the potential to implement innovative actions to support mitigation policies and local sustainable development. 


\section{Acknowledgements}

The authors would like to thank Alessandra Anacleto and all the participants at the initial workshop organized by the Municipality of Cascina. In particular, Alessio Antonelli, former Mayor of Cascina, and all the members of the local Government Council, Marco Ricci and Sergio Mottola who contributed their knowledge and experience during the initial stages of this research project. In addition, we are very grateful to the many participants at the Workshop INOGOV (Innovative urban governance for mitigation and adaptation: Mapping, exploring and interrogation), 35th International Conference of the System Dynamics Society and the 7th International Sustainability Transitions for helpful comments. We are also immensely grateful to Emanuele Campiglio, Davide Fiaschi, Tiziano Razzolini, Jordi Roja and Ashok Thomas for their comments on earlier versions of the manuscript. We finally thank five anonymous reviewers for their comments which improved the manuscript.

\section{References}

Aikenhead, G., K. Farahbakhsh, J. Halbe, and J. Adamowski (2015), “Application of process mapping and causal loop diagramming to enhance engagement in pollution prevention in small to medium size enterprises: case study of a dairy processing facility", Journal of Cleaner Production 102, 275 - 284.

Barbu, A., N. Griffiths, and G. Morton (2013), “Achieving energy efficiency through behaviour change: what does it take?”, Technical report, European Environment Agency.

Bernardo, G. (2016), "A system dynamics approach to economic policies: money, environment and local development", Doctoral Dissertation, University of Pisa.

Bianchi, C. and S. Tomaselli (2015), “A dynamic performance management approach to support local strategic planning”, International Review of Public Administration 20(4), 370-385.

Booream-Phelps, J. and V. Shah (2015), "Solar grid parity in a low oil price era", Technical report, Deutsche Bank - Markets Research.

Brailsford, S. C., V. A. Lattimer, P. Tarnaras, and J. C. Turnbull (2004), "Emergency and on-demand health care: Modelling a large complex system", The Journal of the Operational Research Society 55(1), 34-42.

Caponio, G., V. Massaro, M. G., and G. Mummolo (2015), "Strategic energy planning of residential buildings in a smart city: A system dynamics approach", International Journal of Engineering Business Management 7:20. 
Carter, J. G., G. Cavan, A. Connelly, S. Guy, J. Handley, and A. Kazmierczak (2015), "Climate change and the city: Building capacity for urban adaptation", Progress in Planning 95, 1-66.

Cayuela, D. B., R. P. de Raveschoot, S. Monni, and P. Bertoldi (2009), "Existing methodologies and tools for the development and implementation of seaps", Technical report, EUR 24309 EN “ Joint Research Center" Institute for Energy.

Cipriano, X., G. Gamboa, S. Danov, G. Mor, and J. Cipriano (2017). "Developing indicators to improve energy action plans in municipalities: An accounting framework based on the fund-flow model", Sustainable cities and society 32, 263-276.

Cucchiella F., D’Adamo I., Gastaldi M., Koh L., Rosa P., "A comparison of environmental and energetic performance of European countries: A sustainability index",Renewable and Sustainable Energy Reviews,Volume 78,2017,Pages 401-413,ISSN 1364-0321.

De Miglio, R., M. Gargiulo, and L. E (2006), "Integration of comprehensive analysis with sub-system and component modelling tools for local energy planning.", International Energy Workshop 2006 Cape Town(South Africa), 27-29 June 2006.

Delponte, I., I. Pittaluga, and C. Schenone (2017), "Monitoring and evaluation of sustainable energy action plan: practice and perspective.”, Energy Policy 100, 9-17.

Dent, C., C. Bale, Z. Wadud, , and H. Voss (2016), "Cities, energy and climate change mitigation.", Cities $\operatorname{May}(54), 1-3$.

Duran-Encalada, J. A. and A. Paucar-Caceres (2008). "System dynamics urban sustainability model for puerto aura in puebla, Mexico.", Systemic Practice and Action Research 22(2), 77-99.

Edwards, M. M. and A. Haines (2007), "Evaluating smart growth: Implications for small communities.", Journal of Planning Education and Research 27(1), 49-64.

Feng, Y., S. Chen, and L. Zhang (2013), "System dynamics modeling for urban energy consumption and $\mathrm{CO} 2$ emissions: A case study of beijing, china", Ecological Modelling 252, 44 - 52. Ecological Modelling for Global Change and Coupled Human and Natural Systems.

Fong, W.-K., H. Matsumoto, and Y.-F. Lun (2009), "Application of system dynamics model as decision making tool in urban planning process toward stabilizing carbon dioxide emissions from cities.", Building and Environment 44(7), 1528 - 1537. The 6th International Conference on Indoor Air Quality, Ventilation and Energy Conservation in Buildings (IAQVEC 2007), Sendai, Japan, 28-31 October, 2007.

Forrester, J. W. (1969), “Urban Dynamics”, MIT Press: Cambridge, MA. 
Frey, C. (2018), "Multilevel network governance of disaster risks: the case of the Metropolitan Region of the Aburra Valley", Journal of Environmental Planning and Managment, this issues.

Georgi, B., R. Swart, N. Marinova, B. Van Hove, C. Jacobs, and J. Klostermann (2012), "Urban adaptation to climate change in Europe: Challenges and opportunities for cities together with supportive national and European policies", Number 2/2012. EEA.

GSE (2014), "Solare termico - rapporto statistico 2014", Technical report, Gestore Servizi Energetici.

Hennessy, G., J. Cook, M. Bean, and K. Dykes (28 July 2011), "Economic dynamics for smarter cities.", In:Proceedings of the International Conference of the System Dynamics Society, Washington, USA.

Homsy, G. C. and M. E. Warner (2015). "Cities and sustainability: Polycentric action and multilevel governance.”, Urban Affairs Review 51(1), 46-73.

Hong, T., S. C. Taylor-Lange, Doca, S. , D. Yan, and S. P. Corgnati (2016), "Advances in research and applications of energy-related occupant behavior in buildings.", Energy and Buildings 116, $694-702$.

Hoppe, T., A. van der Vegt, and P. Stegmaier (2016), "Presenting a framework to analyze local climate policy and action in small and medium-sized cities.”, Sustainability (8(9)).

Hunt, A. and P. Watkiss (2011), "Climate change impacts and adaptation in cities: a review of the literature.", Climatic Change 104(1), 13-49.

Inam, A., J. Adamowski, J. Halbe, and S. Prasher (2015), "Using causal loop diagrams for the initialization of stakeholder engagement in soil salinity management in agricultural watersheds in developing countries: A case study in the rechna doab watershed, Pakistan.", Journal of Environmental Management 152, 251 - 267.

Jakeman, A. J., R. A. Letcher, and J. P. Norton (2006), "Ten iterative steps in development and evaluation of environmental models.", Environmental Modelling \& Software 21(5), 602-614.

Kern, K. (2014), "Climate governance in the european union multilevel system: The role of cities.", Multilevel environmental governance.", Managing water and climate change in Europe and North America, 111-130.

Khan, Z., P. Linares, M. Rutten, S. Parkinson, N. Johnson, and J. García-González (2018), "Spatial and temporal synchronization of water and energy systems: Towards a single integrated optimization model for long-term resource planning.", Applied Energy 210, $499-517$. 
Knox, P. and H. Mayer (2013), "Small town sustainability: Economic, social, and environmental innovation.", Walter de Gruyter.

Knox, P. L. and H. Mayer (2012), "Europe's internal periphery: Small towns in the context of reflexive polycentricity.".

Levesque, V. R., K. P. Bell, and A. J. Calhoun (2016), "Planning for sustainability in small municipalities the influence of interest groups, growth patterns, and institutional characteristics.", Journal of Planning Education and Research.

Liu, G., S.-W. Amakpah, Z. Yang, B. Chen, Y. Hao, and S. Ulgiati (2016), "The evolution of cities: "brains" or "parasites" of sustainable production and consumption processes in china.", Energy Procedia 88, 218 - 223. CUE 2015 - Applied Energy Symposium and Summit 2015: Low carbon cities and urban energy systems.

Lubell, Mark N.and Feiock, R. C. and S. Handy (2009), "City adoption of environmentally sustainable policies in California's Central Valley.”, Journal of the American Planning Association 75 (3).

Marinakis, V., H. Doukas, P. Xidonas, and C. Zopounidis (2017), "Multicriteria decision support in local energy planning: An evaluation of alternative scenarios for the sustainable energy action plan.", Omega 69, 1- 16.

Martín-Gamboa, M., D. Iribarren, D. García-Gusano, and J. Dufour (2017), "A review of life-cycle approaches coupled with data envelopment analysis within multi-criteria decision analysis for sustainability assessment of energy systems.", Journal of Cleaner Production 150, $164-174$.

Masoso, O. and L. Grobler (2010), "The dark side of occupants behaviour on building energy use.", Energy and Buildings 42(2), 173 - 177.

McPhearson, T., S. Parnell, D. Simon, O. Gaffney, T. Elmqvist, X. Bai, and A. Revi (2016), "Scientists must have a say in the future of cities.", Nature (538), 165-166.

Medda, F., C. Partridge, G. Carbonaro, A. Vesco, and F. Ferrero (2015), "Energy investment in smart cities. unlocking financial instruments in europe.”, In Handbook of Research on Social, Economic, and Environmental Sustainability in the Development of Smart Cities, pp. 408-433. IGI Global Hershey, PA.

Miller, J. R., M. Groom, G. R. Hess, T. Steelman, D. L. Stokes, J. Thompson, T. Bowman, L. Fricke, B. King, and R. Marquardt (2009), "Biodiversity conservation in local planning.", Conservation Biology 23(1), 53-63.

Mirakyan, A. and R. D. Guio (2013), "Integrated energy planning in cities and territories: A review of methods and tools.", Renewable and Sustainable Energy Reviews 22, $289-$ 297. 
Mirakyan, A., L. Lelait, N. Khomenko, and I. Kaikov (2009), "Methodological framework for the analysis and development of a sustainable, integrated, regional energy plan? a French region case study.", EcoMod.

Nocera, M. (2014), “Rapporto annuale efficienza energetica.", Technical report, ENEA Department of Energy Efficiency.

Oliva, R. (2003), "Model calibration as a testing strategy for system dynamics models.", European Journal of Operational Research 151(3), 552 - 568.

Oosthuizen, R. and L. Pretorius (2015, Nov), "System dynamics modelling of situation awareness.", Working paper pp. 1-6.

Parkinson, S. C., M. Makowski, V. Krey, K. Sedraoui, A. H. Almasoud, and N. Djilali (2018), “A multi-criteria model analysis framework for assessing integrated water-energy system transformation pathways.”, Applied Energy 210, 477 - 486.

Salvia, M., S. Di Leo, C. Nakos, H. Maras, S. Panevski, O. Fülöp, S. Papagianni, Z. Tarevska, D. Čeh, E. Szabó, et al. (2015), "Creating a sustainable and resource efficient future: A methodological toolkit for municipalities.", Renewable and sustainable energy reviews 50, 480-496.

Sanders, P. and F. Sanders (2004), "Spatial urban dynamics”, In:Proceedings of the 2004 international system dynamics conference, Oxford, UK.

Sarriot, E., M. Morrow, A. Langston, J. Weiss, J. Landegger, and L. Tsuma (2015), “A causal loop analysis of the sustainability of integrated community case management in rwanda.", Social Science and Medicine 131, 147 - 155.

Shepherd, S. (2014), "A review of system dynamics models applied in transportation.", Transportmetrica B: Transport Dynamics 2(2), 83-105.

Sivaev, S., M. Christiansen, M. Milligan, N. Hannula, E. Sirazhitdinova, I. Gentsler, and T. Lykova (2013), "Good practices for energy-efficient housing in the Unece region.", Technical report, United Nations Economic Commission for Europe.

Strachan, N., N. Balta-Ozkan, D. Joffe, K. McGeevor, and N. Hughes (2009), "Softlinking energy systems and gis models to investigate spatial hydrogen infrastructure development in a low-carbon uk energy system.", International Journal of Hydrogen Energy pp. $34-64$.

Sveiby, K., K. Linard, and D. L. (2002), "Building a knowledge-based strategy: A system dynamics model for allocating value-adding capacity.", In Proceedings of the 20th International Conference of the System Dynamics Society , July 28 - Aug 1, 2002, Palermo, Italy. 
Swanson, J. (24 July 2003)., "The dynamic urban model: Transport and urban development.", In:Proceedings of the 21st Systems Dynamics Conference, New York, USA.

Team, B. I. (2011), “Behaviour change and energy use.”, Technical report, Cabinet Office.

Terzini, E., A. De Lillo, A. Di Mario, C. Privato, G. Graditi, A. Di Francia, G. Antonaia, A. Mittiga, P. Delli Veneri, and C. Minarini (2011), "Quaderno fotovoltaico.", Technical report, ENEA.

van der Heijden, J. (2012), "Voluntary environmental governance arrangements.", Environmental Politics 21(3), 486-509.

van der Heijden, J. (2015), "What roles are there for government in voluntary environmental programs?”, RegNet Working Paper (No. 70).

van der Heijden, J. (2016), "The new governance for low-carbon buildings: mapping, exploring, interrogating.", Building Research \& Information 44(5-6), 575-584.

van der Heijden, J. (2018): "Voluntary urban climate programmes: should city governments be involved and, if so, how? ", Journal of Environmental Planning and Management, DOI: 10.1080/09640568.2017.1406344

Viana, J., S. Brailsford, V. Harindra, and P. Harper (2014). Combining discrete-event simulation and system dynamics in a healthcare setting: A composite model for chlamydia infection. European Journal of Operational Research 237(1), 196 - 206.

Videira, N., P. Antunes, and R. Santos (2009), "Scoping river basin management issues with participatory modelling: the baixo guadiana experience.", Ecological Economics 68(4), 965-978.

Videira, N., P. Antunes, R. Santos, and R. Lopes (2010), "A participatory modelling approach to support integrated sustainability assessment processes.”, Systems Research and Behavioral Science 27(4), 446-460.

Voinov, A., N. Kolagani, M. K. McCall, P. D. Glynn, M. E. Kragt, F. O. Ostermann, S. A. Pierce, and P. Ramu (2016), "Modelling with stakeholders-next generation.", Environmental Modelling \& Software 77, 196-220.

While, A. and M. Whitehead (2013), "Cities, urbanisation and climate change.", Urban Studies 50(7), 1325-1331.

Wilson, E. (2006), "Adapting to climate change at the local level: the spatial planning response”, Local Environment 11(6), 609-625. 


\section{List of Tables}

Table 1: Cascina: Consumption of Energy and $\mathrm{CO}_{2}$ emissions by Sector

\begin{tabular}{l|c|c|c|c} 
& Energy Use & $\mathrm{CO}_{2}$ Emission & Energy Use \% & $\mathrm{CO}_{2}$ Emission \% \\
\hline Transport & $298942 \mathrm{MWh}$ & $77647 t \mathrm{CO}_{2}$ & $63 \%$ & $45 \%$ \\
\hline Housing & $58268 \mathrm{MWh}$ & $55805 t \mathrm{CO}_{2}$ & $12 \%$ & $32 \%$ \\
\hline Economic activities & $107041 \mathrm{MWh}$ & $37764 t \mathrm{CO}_{2}$ & $23 \%$ & $22 \%$ \\
\hline Municipality and PS & $8229 \mathrm{MWh}$ & $3014 t \mathrm{CO}_{2}$ & $2 \%$ & $2 \%$ \\
\hline Total & $472479 \mathrm{MWh}$ & $174230 t \mathrm{CO}_{2}$ & &
\end{tabular}

Table 2: Direct Action - Municipality (Reduction of $\mathrm{CO}_{2}$ emissions in tons)

\begin{tabular}{|c|c|c|c|c|c|c|}
\hline Actions & 2015 & 2016 & 2017 & 2018 & 2019 & 2020 \\
\hline $\begin{array}{l}\text { Action N.1 - } 2-3 \\
\text { Energy efficiency } \\
\text { Public buildings }\end{array}$ & 136.22 & 177.23 & 218.23 & 259.23 & 300.23 & 341.23 \\
\hline $\begin{array}{c}\text { Action N. } 4 \\
\text { Fotovoltaic power plants }\end{array}$ & 30.72 & 46.08 & 61.44 & 76.81 & 92.17 & 107.53 \\
\hline $\begin{array}{c}\text { Action N. } 5 \\
\text { Solar Thermal Plant } \\
\text { Sport Facilities }\end{array}$ & 4.06 & 8.11 & 12.17 & 16.23 & 20.29 & 24.34 \\
\hline $\begin{array}{c}\text { Action N. } 6 \\
\text { Nursery school - FV }\end{array}$ & 14.53 & 14.53 & 14.53 & 14.53 & 14.53 & 14.53 \\
\hline $\begin{array}{c}\text { Action N. } 7 \\
\text { Public swimming pool } \\
\text { biomass plant }\end{array}$ & 240 & 240 & 240 & 240 & 240 & \\
\hline $\begin{array}{c}\text { Action N. } 8 \\
\text { Energy efficiency } \\
\text { street litghing }\end{array}$ & 852.41 & 898.47 & 944.52 & 990.58 & 1036.63 & 1082.69 \\
\hline $\begin{array}{c}\text { Action N. } 9 \\
\text { Fuel efficiency } \\
\text { municipal vehicles }\end{array}$ & 7.42 & 14.84 & 22.26 & 29.68 & 37.1 & 44.52 \\
\hline $\begin{array}{c}\text { Action N. } 31 \\
\text { Fotovoltaic power plants } \\
\text { public retirement home }\end{array}$ & & 21.19 & 21.19 & 21.19 & 21.19 & 21.19 \\
\hline
\end{tabular}


Table 3: Direct Action - Other Sectors (Reduction of $\mathrm{CO}_{2}$ emissions in tons)

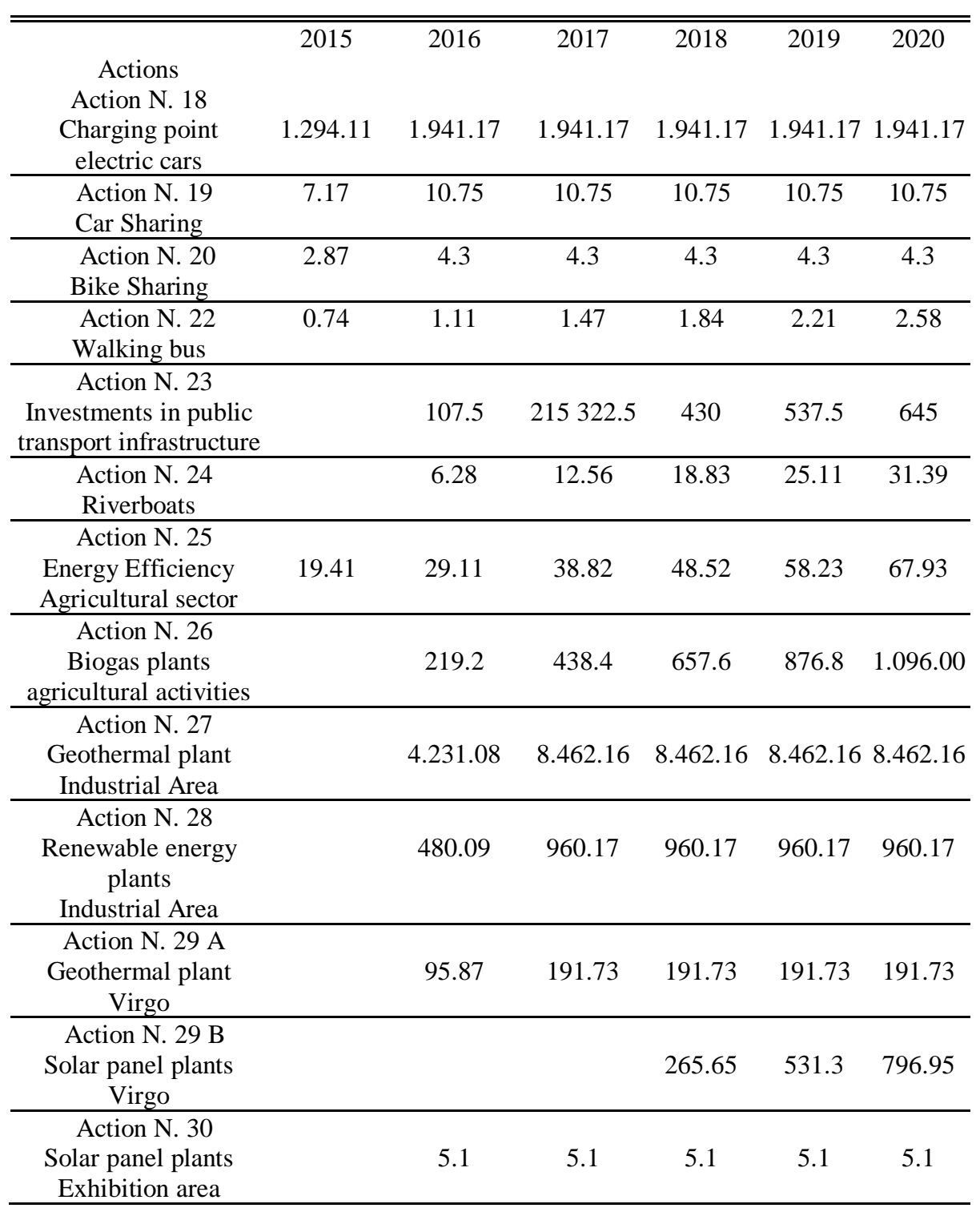


Table 4: Indirect Actions (Reduction of $\mathrm{CO}_{2}$ emissions in tons )

\begin{tabular}{ccccccc}
\hline \hline & 2015 & 2016 & 2017 & 2018 & 2019 & 2020 \\
$\begin{array}{c}\text { Action N. 12 } \\
\text { Energy desk }\end{array}$ & & & & & & \\
\hline $\begin{array}{c}\text { Action N. 17 } \\
\text { Revolving Loans } \\
\text { Buildings }\end{array}$ & & & & & & \\
\hline $\begin{array}{c}\text { Action N. 13 } \\
\text { Solar panel plants } \\
\text { Buildings }\end{array}$ & 1.688 .30 & 2.532 .45 & 3.376 .60 & 4.220 .74 & 5.064 .89 & 5.909 .04 \\
\hline $\begin{array}{c}\text { Action N. 14 } \\
\text { Geothermal plants } \\
\text { Buildings }\end{array}$ & 29.63 & 59.25 & 88.88 & 118.51 & 148.13 & 177.76 \\
\hline $\begin{array}{c}\text { Action N. 15 } \\
\text { Energy efficiency } \\
\text { Buildings }\end{array}$ & 1.611 .86 & 2.417 .79 & 3.223 .73 & 4.029 .66 & 4.835 .59 & 5.641 .52 \\
\hline $\begin{array}{c}\text { Action N. 21 } \\
\text { Fuel efficiency } \\
\text { campaign for cars }\end{array}$ & 1.242 .35 & 1.863 .52 & 2.484 .69 & 3.105 .86 & 3.727 .04 & 4.348 .21 \\
\hline $\begin{array}{c}\text { Action N. 33 } \\
\text { Revolving loans } \\
\text { Firms }\end{array}$ & 810.94 & 1621.87 & 2432.81 & 3243.75 & 4054.69 & 4865.62 \\
\hline
\end{tabular}

Table 5: CASCINA SEAP vs Model simulation: $\mathrm{CO}_{2}$ emissions saving by Sector

\begin{tabular}{l|l|l} 
& Cascina SEAP & Model Simulation \\
\hline Transport & $5042.35 t C O^{2}$ & $6454.7 t C O^{2}$ \\
\hline Public Sector & $1836.49 t C O^{2}$ & $2159.1 t C O^{2}$ \\
\hline Household & $11728.3 t C O^{2}$ & $10947.4 t C O^{2}$ \\
\hline Firms & $16440.56 t C O^{2}$ & $15212.1 t C O^{2}$ \\
\hline Total & $35047.7 t C O^{2}$ & $34773.3 t C O^{2}$
\end{tabular}


Table 6: Reduction of average parameter in awareness scenario

\begin{tabular}{lcccccc}
\hline \hline & & 2015 & & & 2020 & \\
\hline & BAU & SEAP & SEAP AW & BAU & SEAP & SEAP AW \\
\hline $\begin{array}{l}\text { Average cons. } \\
\text { electricity }\end{array}$ & 2.48 & 2.48 & 2.48 & 2.48 & 2.48 & 2 \\
\hline $\begin{array}{l}\text { Average cons. } \\
\text { methan } 29\end{array}$ & 8.9 & 8.9 & 8.9 & 8.9 & 8.9 & 8.43 \\
\hline $\begin{array}{l}\text { Average KM } \\
\text { Diesel car }\end{array}$ & 13602 & 13602 & 13602 & 13573 & 13284 & 12570 \\
\hline $\begin{array}{l}\text { Average KM } \\
\text { Gasoline car }\end{array}$ & 8850 & 8850 & 8850 & 8919 & 8778 & 8307 \\
$\begin{array}{l}\text { Total } \\
\text { Investment } \\
\text { efficiency }\end{array}$ & 2.5 & 2.7 & 2.7 & 1.4 & 1.9 & 2.4 \\
$\begin{array}{l}\text { Total } \\
\begin{array}{l}\text { Investment } \\
\text { Solar panel }\end{array}\end{array}$ & 3 & 3.9 & 3.9 & 2.5 & 3.2 & 4.4 \\
\hline
\end{tabular}

${ }^{28}$ Value expressed in MW per year

29 This value corrisponds to the annual avarege use of methan expessed in MW

${ }^{30}$ Value expressed milion of euro

${ }^{31}$ Value expressed milion of euro 


\section{List of Figures}

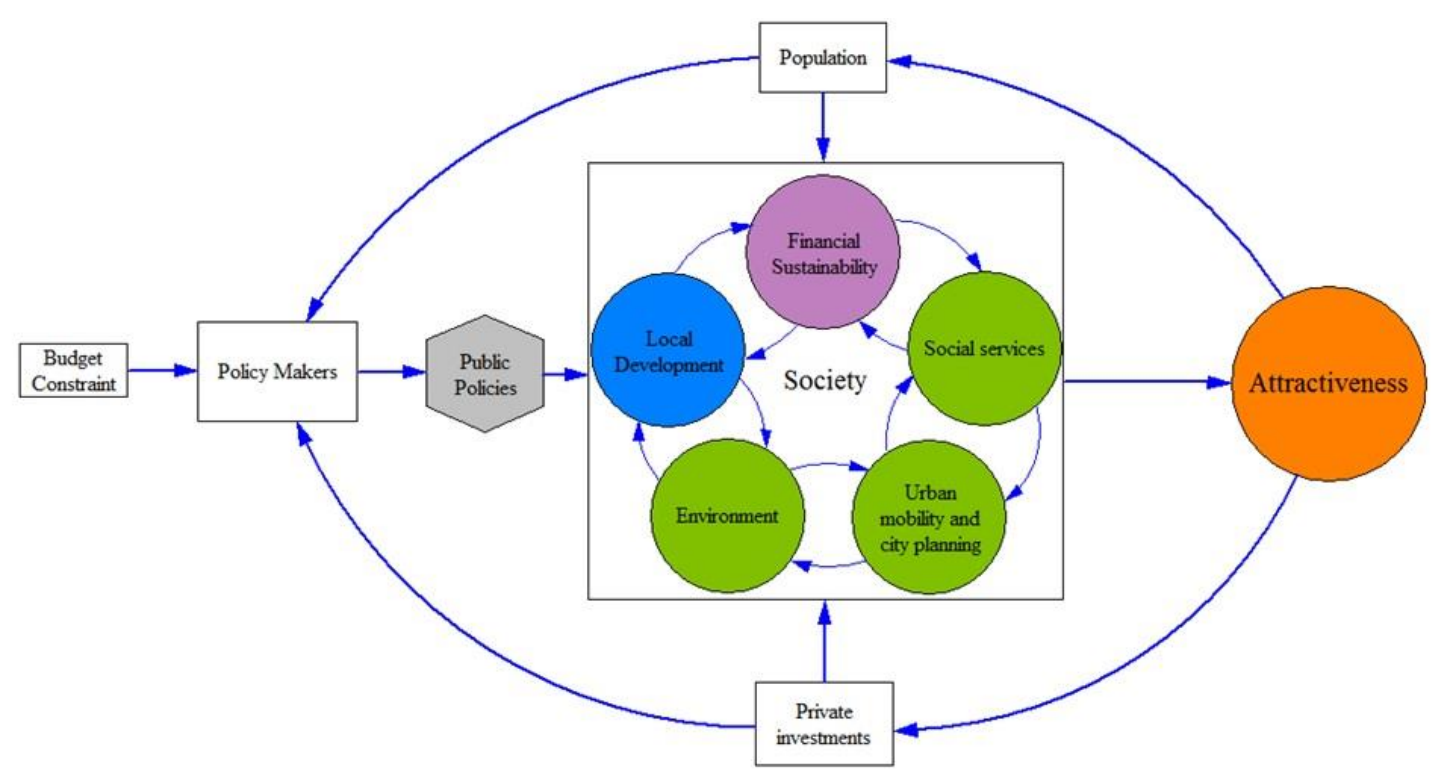

Figure 1: Partecipatory system mapping - Macroview

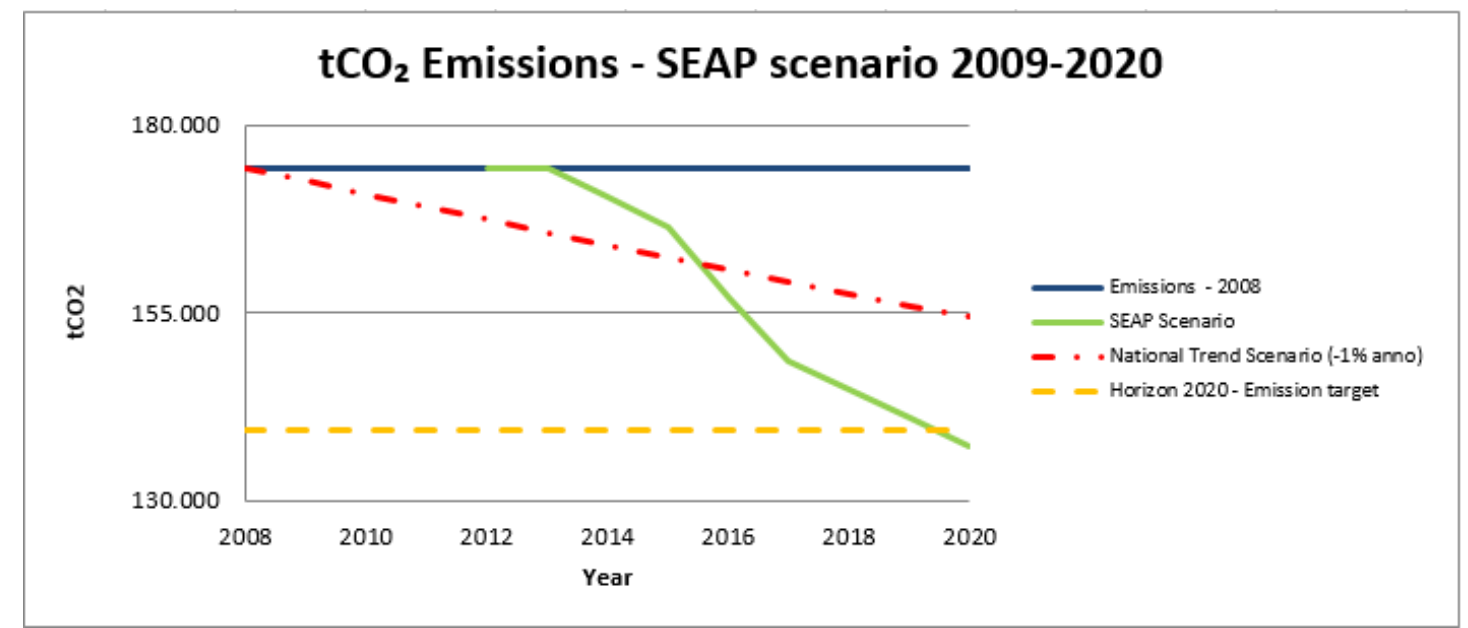

Figure 2: SEAP - Scenario 2009-2020 provided by the Munipality of Cascina 


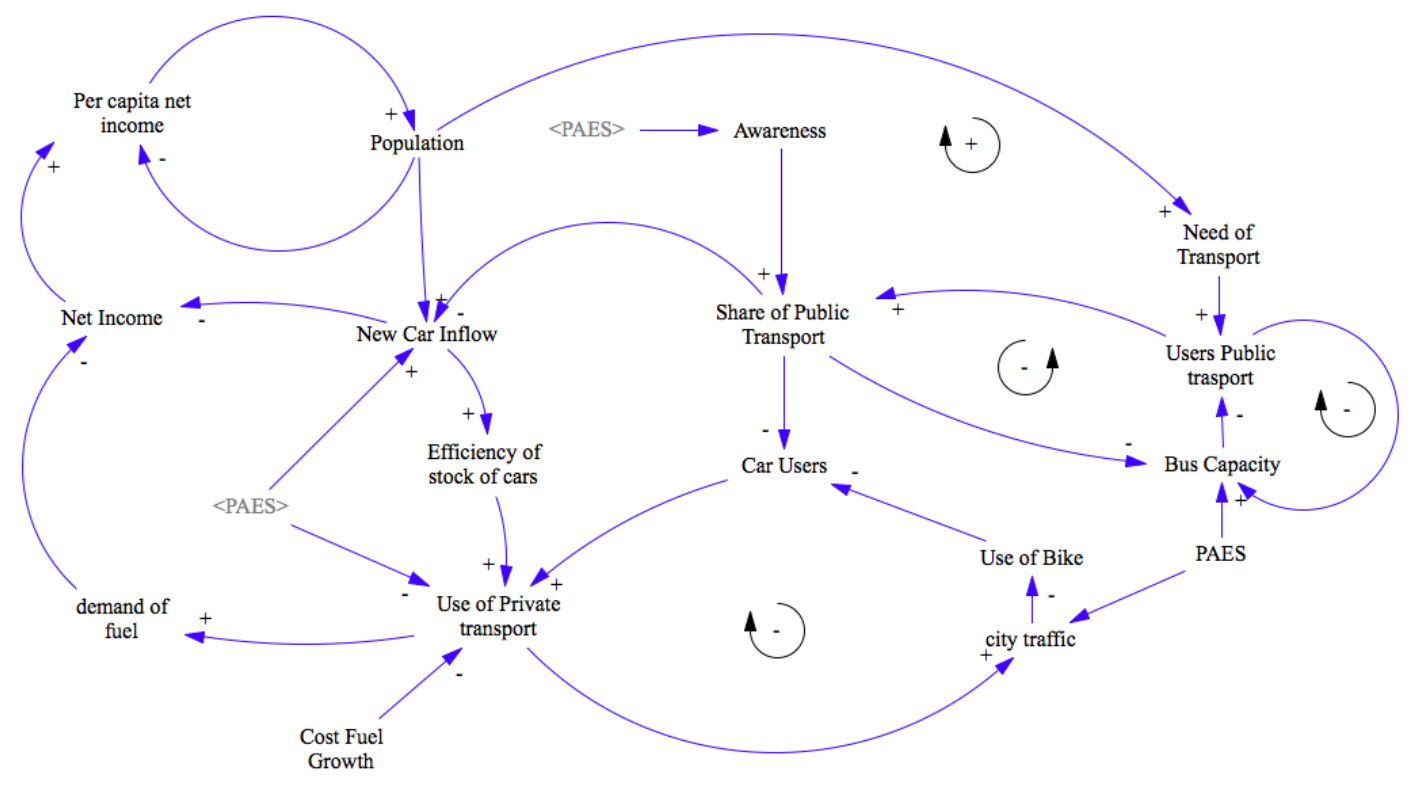

Figure 3: Transport Module

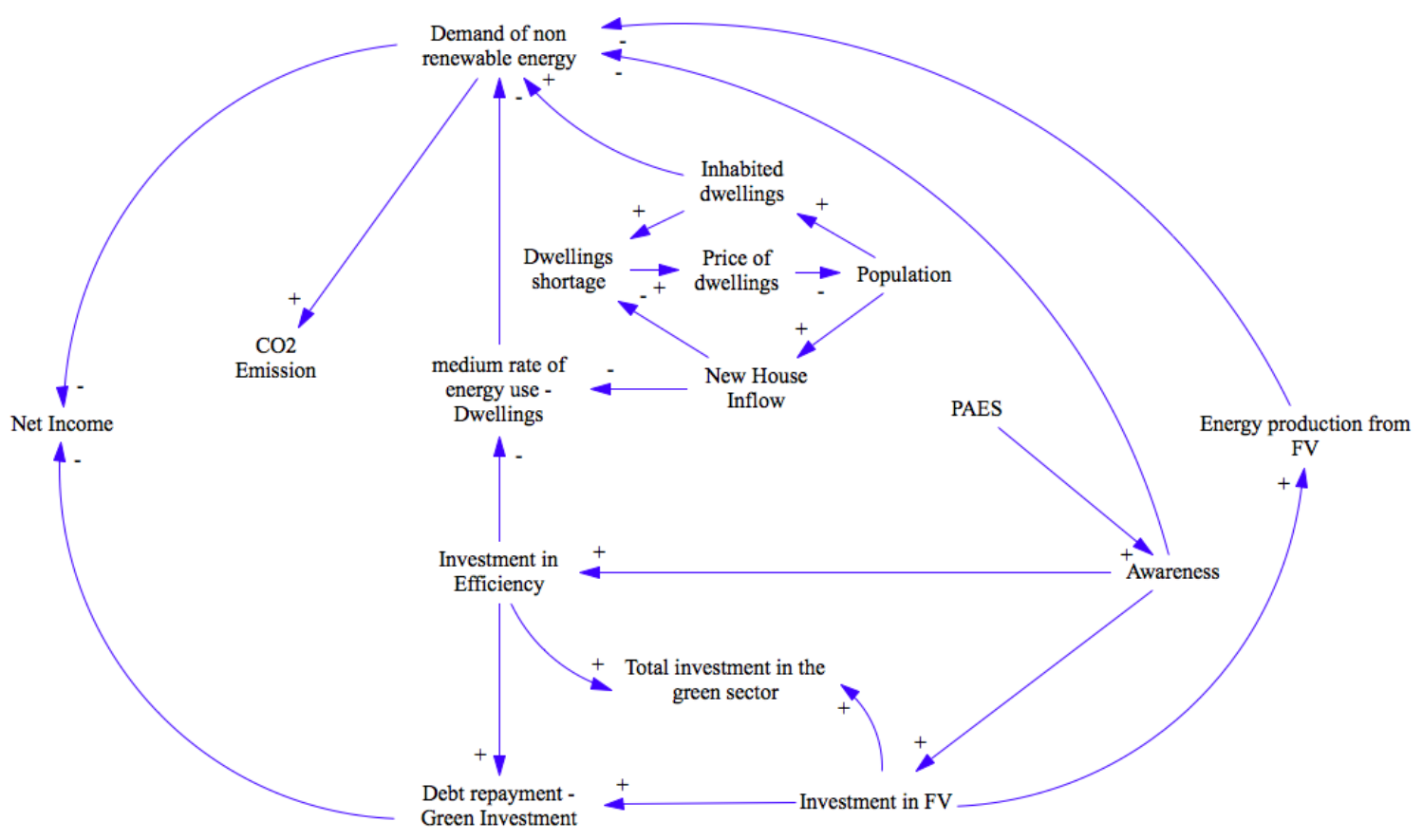

Figure 4: Household 


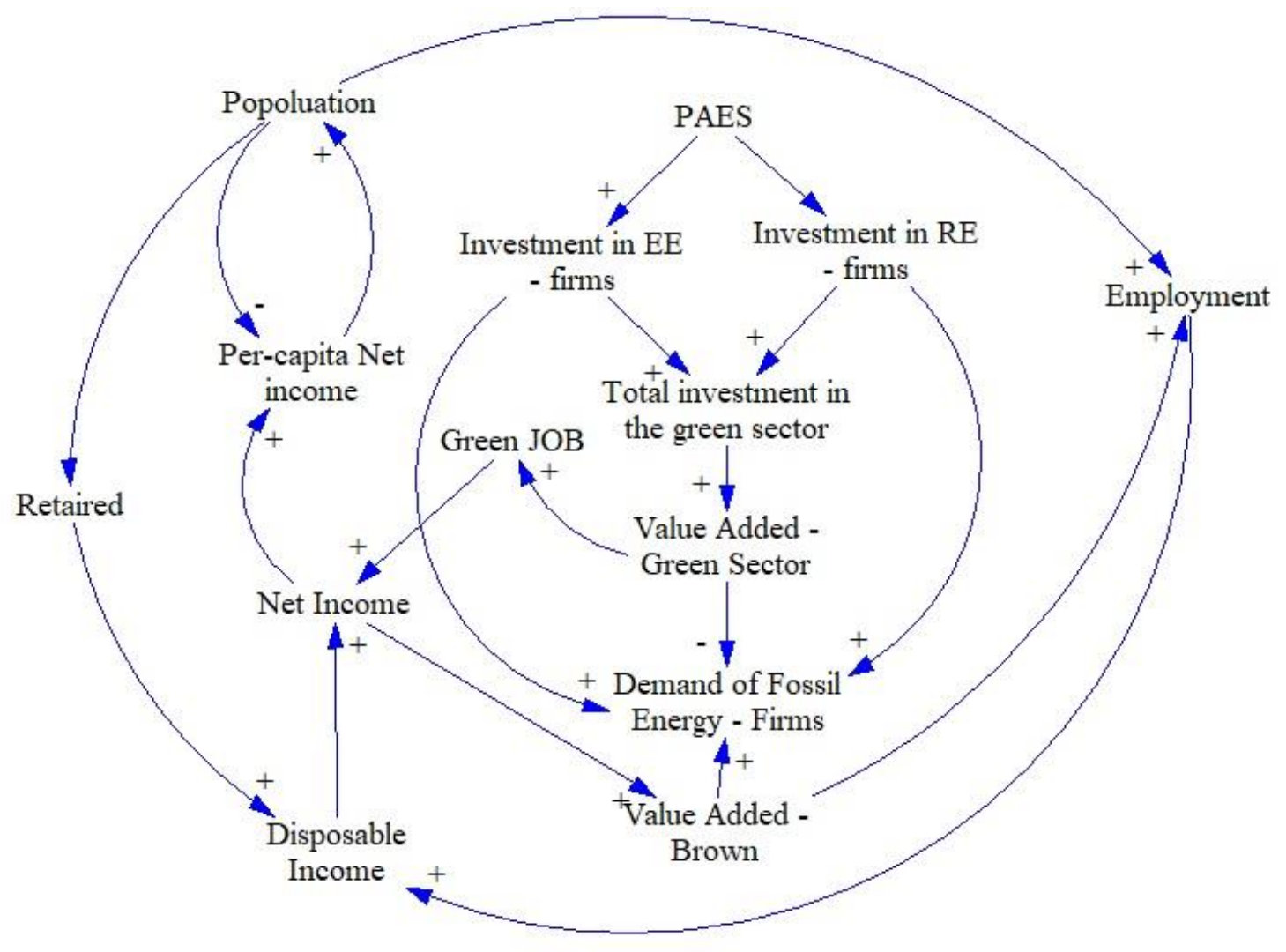

Figure 5: Economy Module

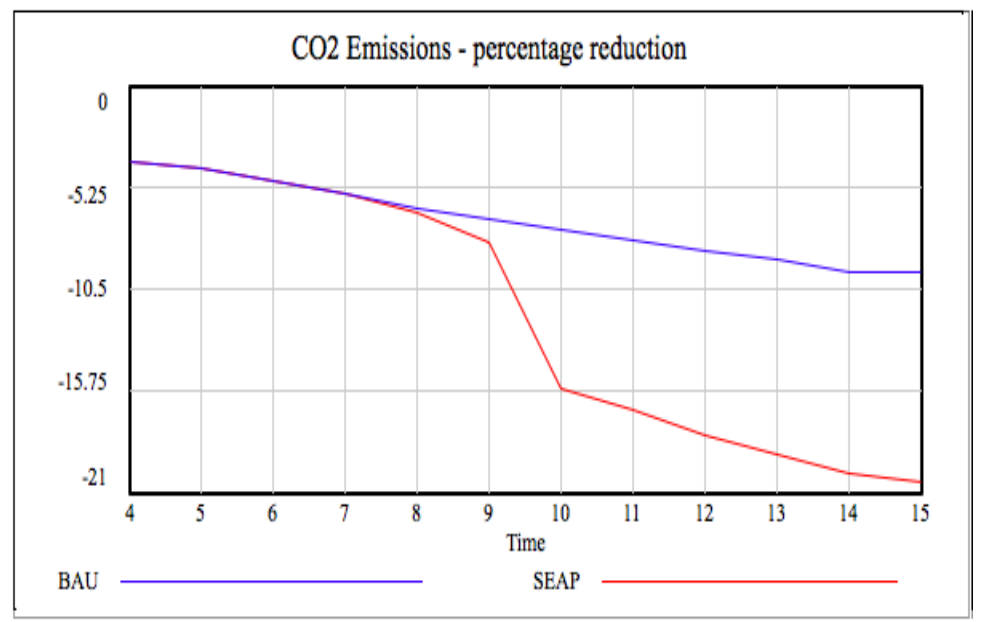

Figure 6: $\mathrm{CO}_{2}$ emissions reduction - No population Growth 


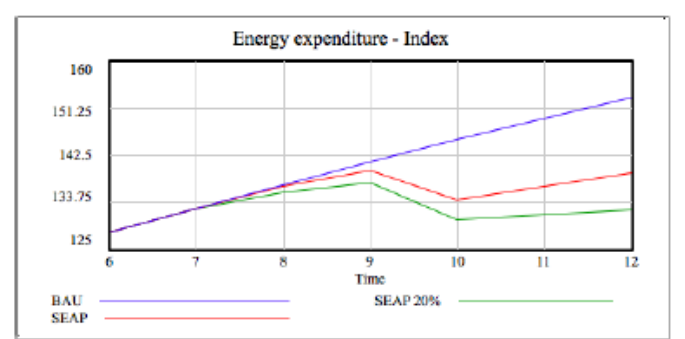

(a)

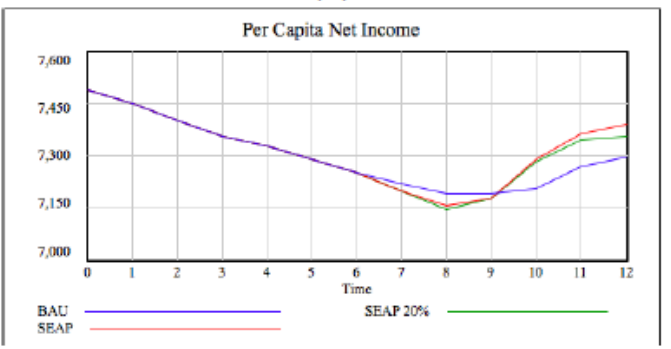

(c)

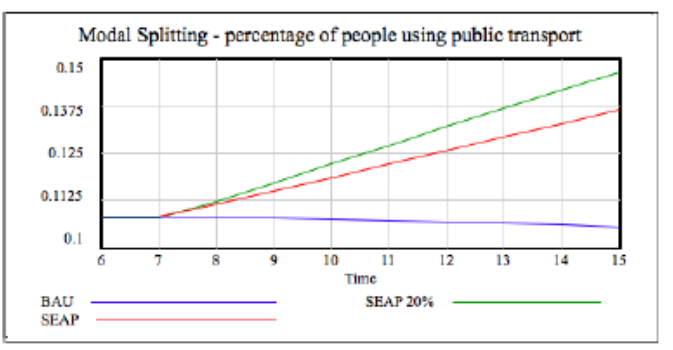

(e)

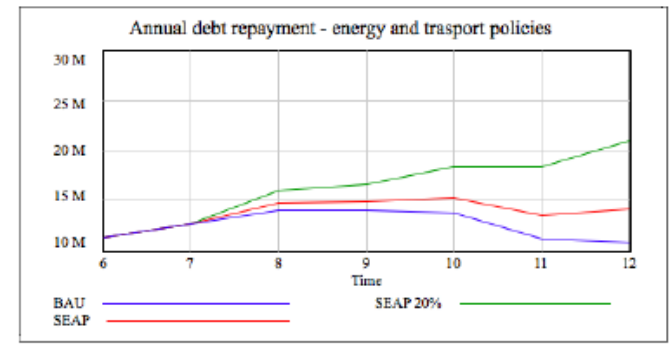

(b)

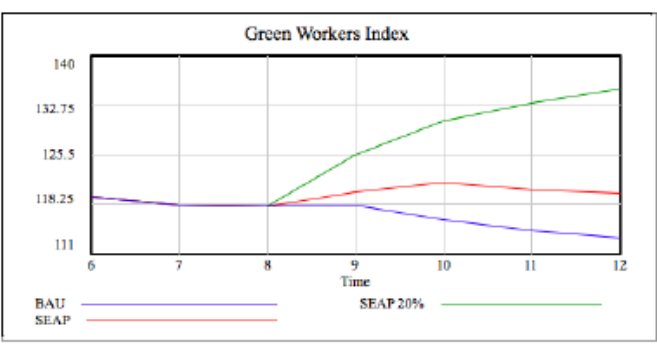

(d)

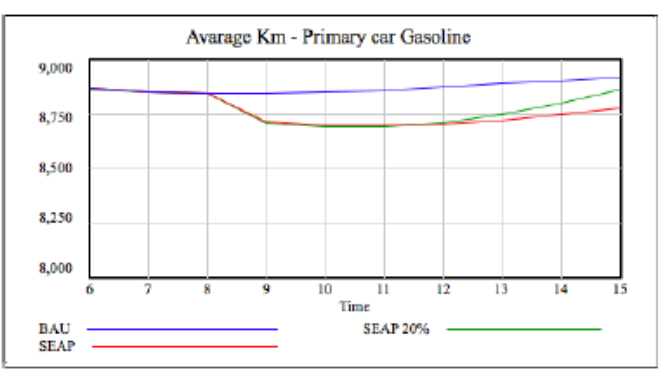

(f)

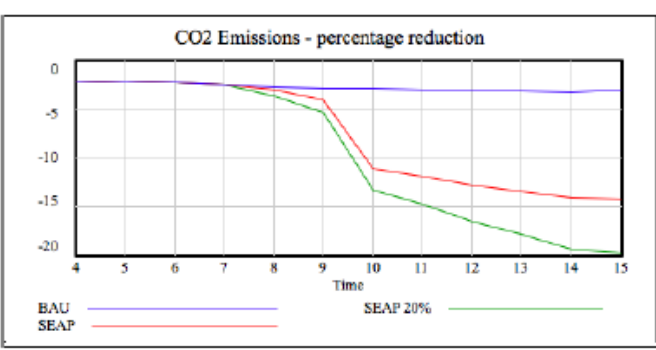

(g)

Figure 7: Scenario Analysis: BAU, SEAP and SEAP 20\% 


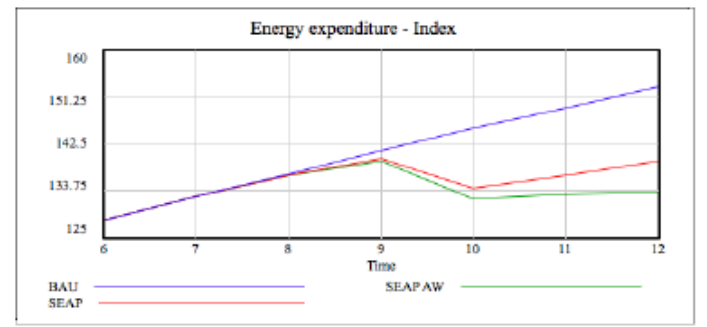

(a)

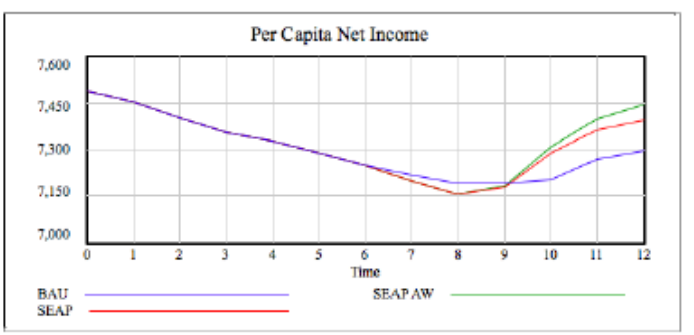

(c)

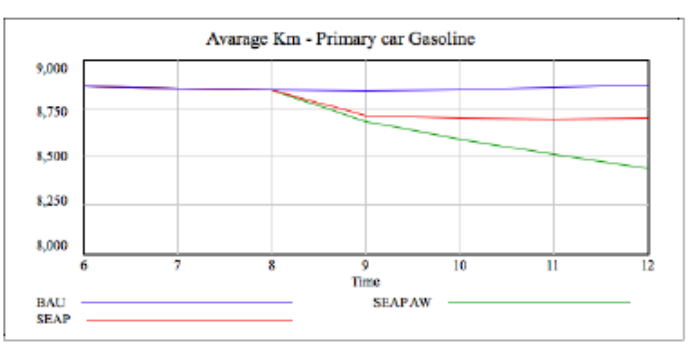

(e)

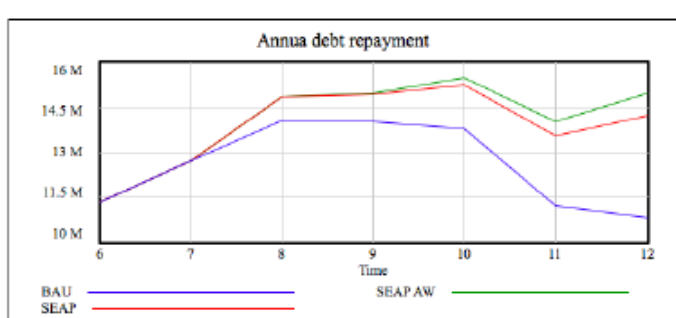

(b)

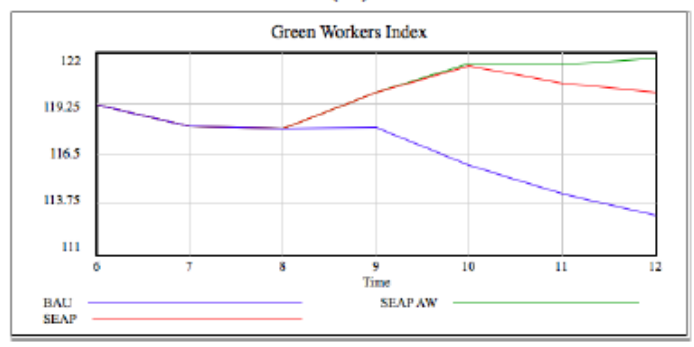

(d)

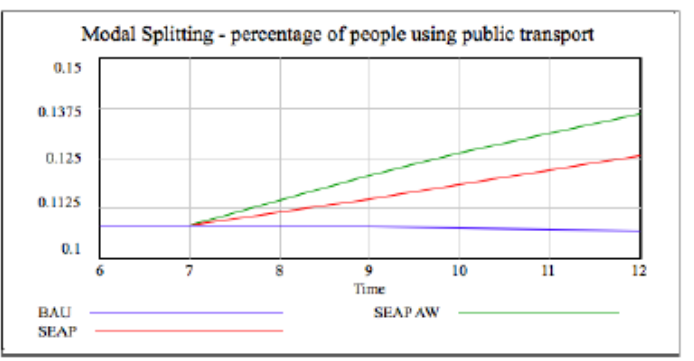

(f)

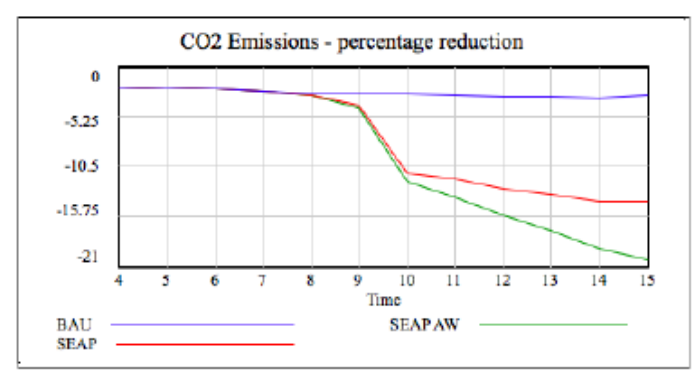

(g)

Figure 8: Scenario Analysis: BAU, SEAP and SEAP Awareness 


\section{A Appendix A - Partecipatory System Approach}

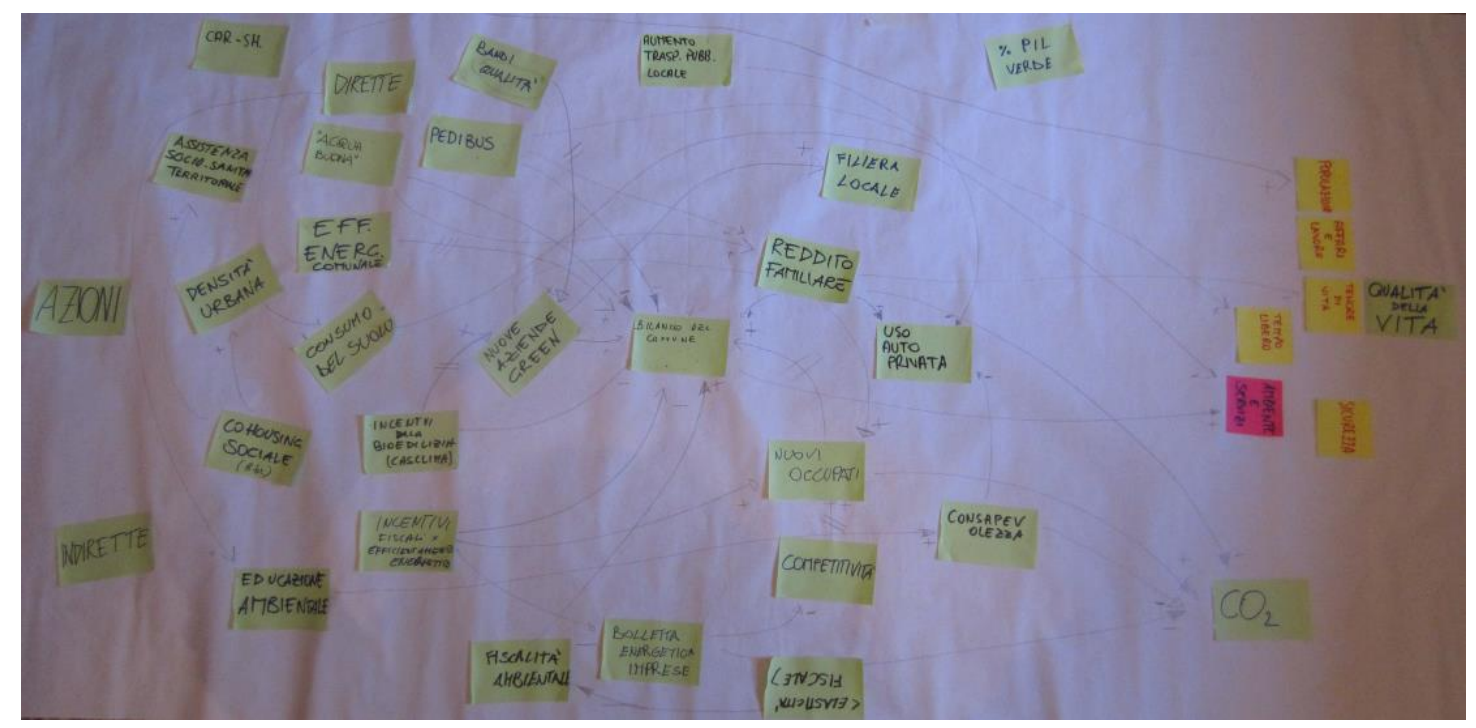

Figure A.1 : Causal map

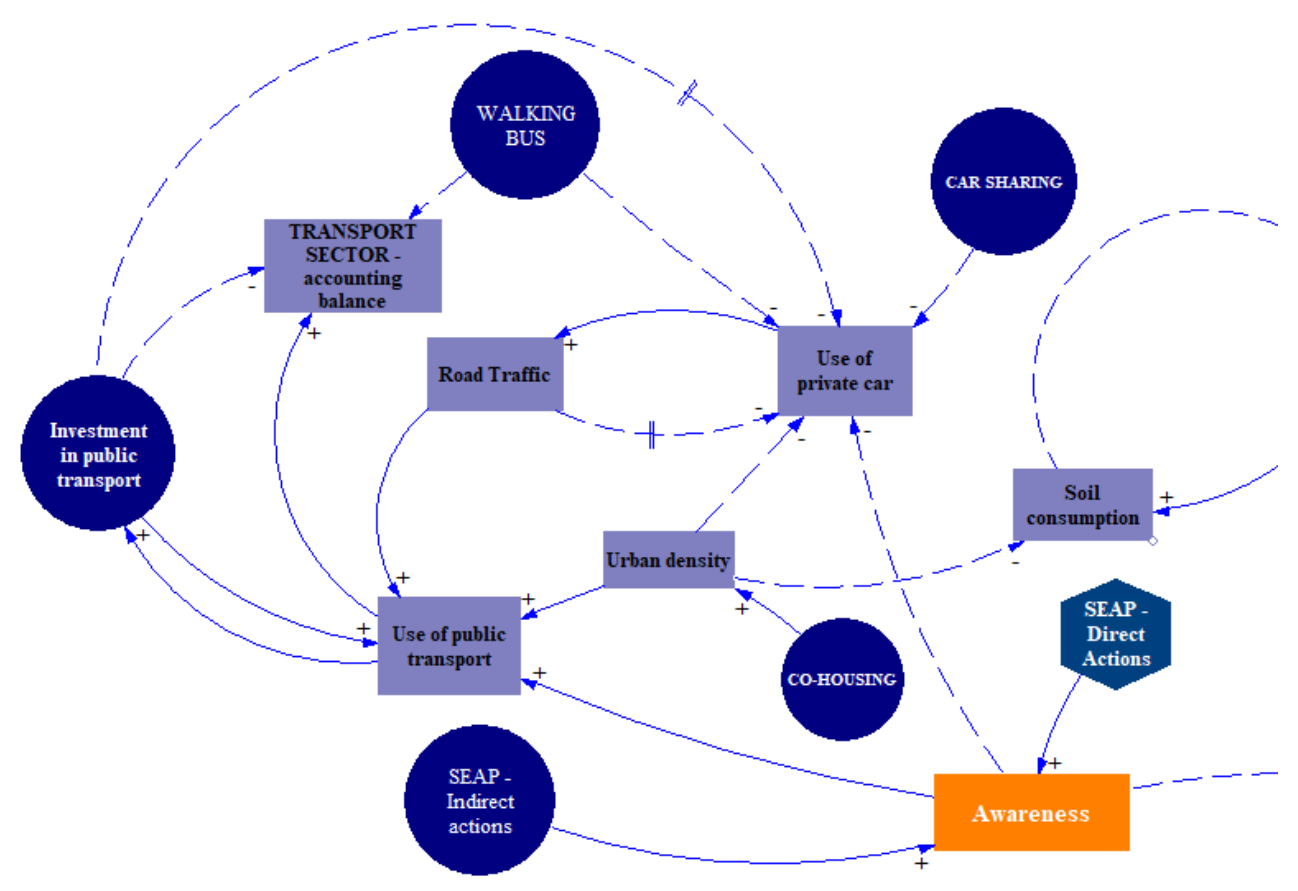

Figure A.2 : Causal Map - Transport sector 


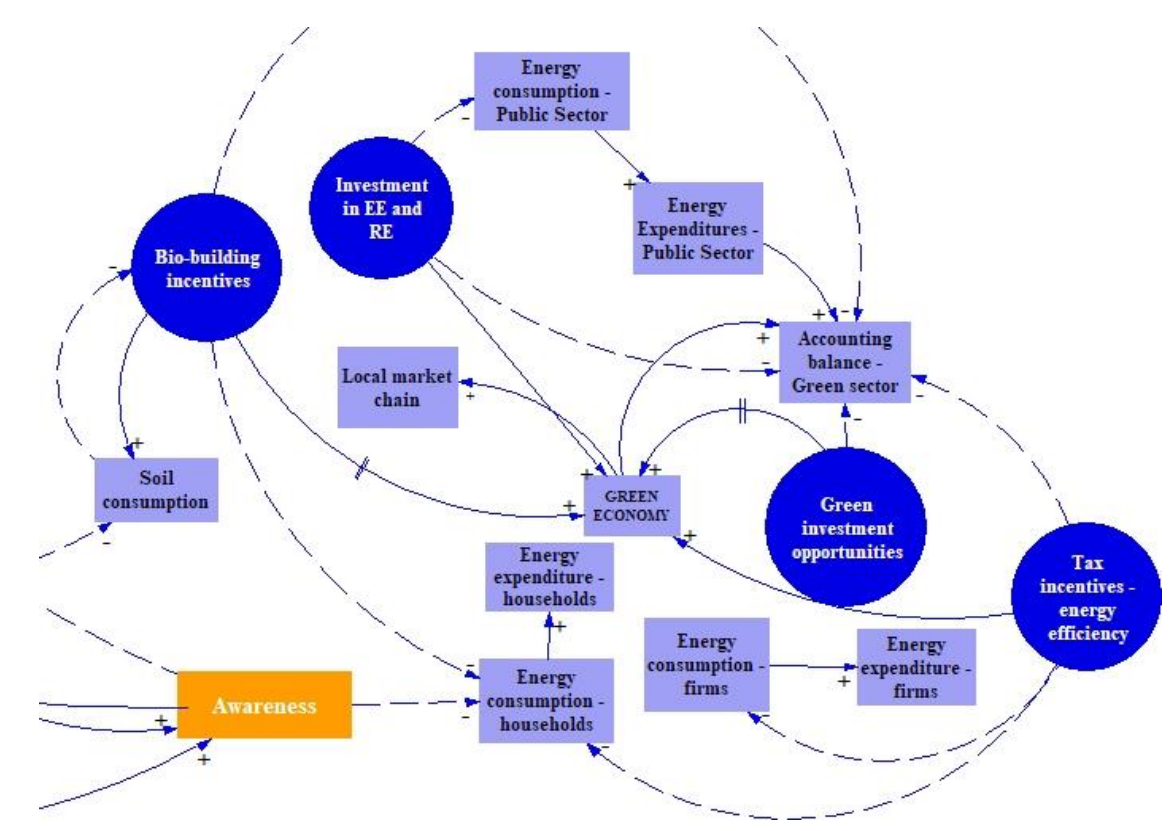

Figure A.3: Causal Map - Energy Sector

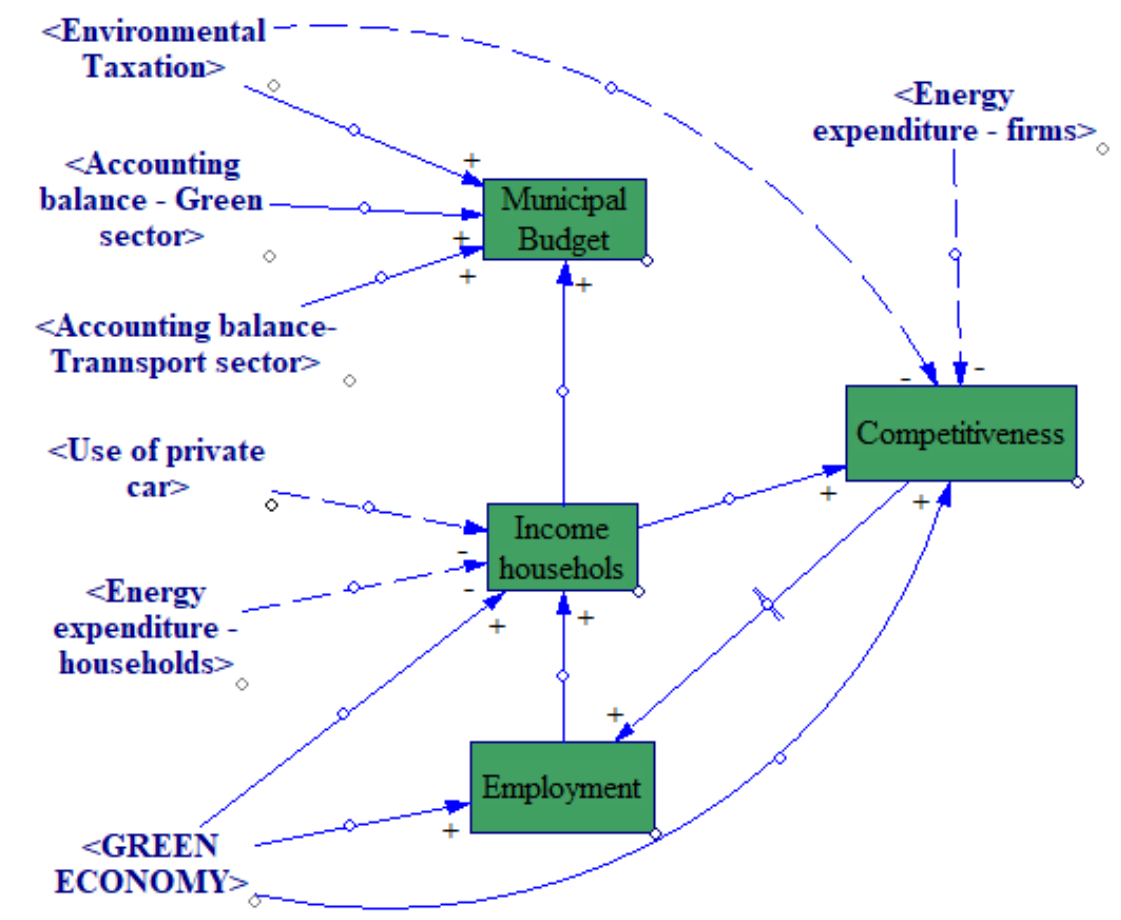

Figure A.4: Causal Map - Municipal Budget and Local Economy 


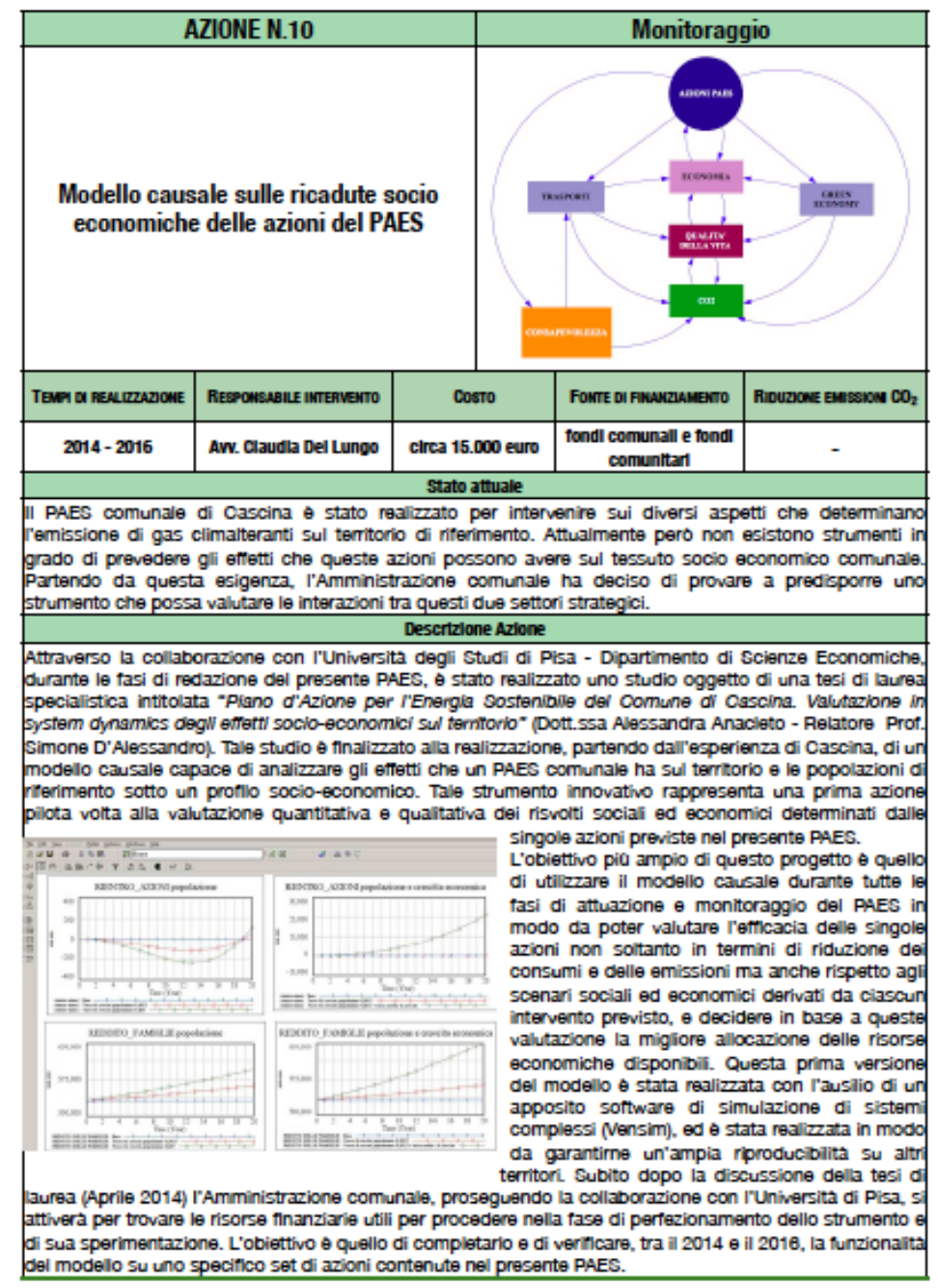

COMUNE di Crsciva - Focus Eunope

Figure A.5: The realization of the research was one of the SEAP Action 